\title{
The Effect of the Stress Path on Squeezing Behavior in Tunneling
}

\author{
Linard Cantieni · Georgios Anagnostou
}

Received: 22 January 2008/ Accepted: 30 September 2008/Published online: 9 December 2008

(C) Springer-Verlag 2008

\begin{abstract}
The interplay between support systems and the rock when tunneling under squeezing conditions is normally studied by means of two-dimensional analyses. The present paper shows that the underlying plane strain assumption involved in a two-dimensional analysis may lead, under certain conditions, to ground pressure and deformation values that are considerably lower than those produced by stress analyses that take into account spatial effects in the vicinity of the tunnel face. The differences are due to the stress path dependency in the elastoplastic behavior of the ground and, more specifically, to the inability of the plane strain model to map the actual radial stress history, which involves a complete radial unloading (and, later, a re-loading) of the tunnel boundary over the unsupported span. This inherent weakness of any plane strain analysis is relevant from the design standpoint, particularly for heavily squeezing conditions that require a yielding support. For the majority of tunneling conditions and methods, however, involving as they do the completion of a stiff support within a few meters of the face, the errors introduced by the plane strain assumption are not important from a practical point of view.
\end{abstract}

Keywords Squeezing - Tunneling - Stress history - Stress path ·

Convergence-confinement

$\begin{array}{ll}\text { List of Symbols } \\ a & \text { Tunnel radius } \\ c & \text { Ground cohesion } \\ d & \text { Lining thickness } \\ \mathrm{d} \lambda_{1,2} & \text { Plastic multipliers }\end{array}$

L. Cantieni $(\bowtie) \cdot$ G. Anagnostou

ETH Zurich, Switzerland

e-mail: linard.cantieni@igt.baug.ethz.ch 


\begin{tabular}{|c|c|}
\hline$E$ & Young's modulus of the ground \\
\hline$E_{\mathrm{L}}$ & Young's modulus of the lining \\
\hline$e$ & Unsupported span \\
\hline$f_{\mathrm{c}}$ & Uniaxial compressive strength \\
\hline$F$ & Function defined by Eq. 6 \\
\hline$g_{1,2}$ & Plastic potential functions \\
\hline$k$ & Lining stiffness \\
\hline$m$ & Material constant defined by Eq. 4 \\
\hline$p$ & Radial pressure acting upon the lining \\
\hline$p(\infty)$ & Final radial pressure acting upon the lining \\
\hline $\bar{p}$ & Transformation of pressure $p$ (Eq. 4) \\
\hline$r$ & Radial co-ordinate (distance from tunnel axis) \\
\hline$s$ & Round length in the step-by-step calculations \\
\hline$u$ & Radial displacement \\
\hline$u(\infty)$ & Final radial displacement of the ground at $r=a$ \\
\hline $\bar{u}$ & Radial displacement (unsupported opening) \\
\hline $\bar{u}_{\mathrm{E}}$ & Radial displacement (unsupported opening, elastic ground) \\
\hline$y$ & Axial co-ordinate (distance behind the tunnel face) \\
\hline$\delta_{1}, 2, \ldots$ & Material constants defined by Eq. 4 \\
\hline$\varepsilon_{y y}$ & Axial strain \\
\hline$\varepsilon_{r r}$ & Radial strain \\
\hline$\varepsilon_{t t}$ & Tangential strain \\
\hline$\varepsilon_{r y}$ & Shear strain \\
\hline$\varepsilon_{\ldots, \text { el }}$ & Elastic strain \\
\hline$\varepsilon_{\ldots, \mathrm{pl}}$ & Plastic strain \\
\hline$\eta_{1,2,3}$ & Material constants defined by Eq. A32 \\
\hline$\eta_{4}$ & Material constants defined by Eq. A14 \\
\hline$\eta_{5,6}$ & Material constants defined by Eq. A29 \\
\hline$\kappa$ & Material constant defined by Eq. 4 \\
\hline$v$ & Poisson's ratio of the ground \\
\hline$\rho$ & Radius of the plastic zone \\
\hline$\rho^{\prime}$ & Radius of the inner part of the plastic zone \\
\hline$\rho_{2 \mathrm{D}}$ & Radius of the plastic zone under plane strain conditions \\
\hline$\rho_{\mathrm{pl}}$ & Radius of the plastic zone under spatial conditions \\
\hline$\rho_{\text {py }}$ & Radius of zone yielding in the past under spatial conditions \\
\hline $\bar{\sigma}_{\ldots}$ & Transformation of stress $\sigma \ldots$ (Eq. A3) \\
\hline$\sigma_{1}$ & Maximum principal stress \\
\hline$\sigma_{3}$ & Minimum principal stress \\
\hline$\sigma_{a}$ & Radial support pressure \\
\hline$\sigma_{0}$ & Initial stress \\
\hline$\sigma_{y y}$ & Axial stress \\
\hline$\sigma_{r r}$ & Radial stress \\
\hline$\sigma_{t t}$ & Tangential stress \\
\hline$\sigma_{r y}$ & Shear stress \\
\hline$\sigma_{\rho^{\prime}}$ & Radial stress at $r=\rho^{\prime}$ \\
\hline
\end{tabular}


$\phi \quad$ Angle of internal friction of the ground

$\Phi \quad$ Function defined by Eq. 12

$\psi \quad$ Dilatancy angle of the ground

\section{Introduction}

The interaction between the ground and the tunnel lining is well understood in principle (see Lombardi 1971, 1981; Panet and Guellec 1974). In the initial state prevailing before tunnel construction, an equilibrium exists between the core ahead of the tunnel face and the surrounding ground. The ground around the future opening exerts a load upon the core and, vice versa, the core supports the surrounding ground. As the support effect of the core disappears with its excavation, a spatial stress redistribution accompanied by deformations occurs around the working face, and a pressure develops upon the lining, because the latter partially hinders the convergence of the tunnel walls. The magnitude of the loading depends on the magnitude of the deformations constrained by the lining (i.e., on the magnitude of the deformations that would occur in the absence of a lining) and, thus, on the distance between the working face and the location of the lining installation ( $e$ in Fig. 1a). The smaller this distance, the higher will be the load that develops with the progress of excavation. Furthermore, as in any statically undetermined system, the magnitude of the ground pressure depends on the loaddeformation characteristics of both the lining and the ground.

The deformations and rock pressures can be estimated by means of threedimensional numerical models that take into account the sequence of lining installation and excavation works. Due to the high cost of such three-dimensional analyses, however, tunnel design calculations are based, in most cases, upon plane strain models that consider a tunnel cross section. The principle of such twodimensional calculations can be illustrated best by considering the axisymmetric case of a deep cylindrical tunnel. Figure $1 \mathrm{~b}$ shows the characteristic lines of the ground and of the lining. The characteristic line of the rock (the so-called ground response curve) relates the radial displacement of the rock at the excavation boundary to the support pressure, while the characteristic line of the lining relates the radial displacement of the lining to the pressure exerted by the rock. The intersection point

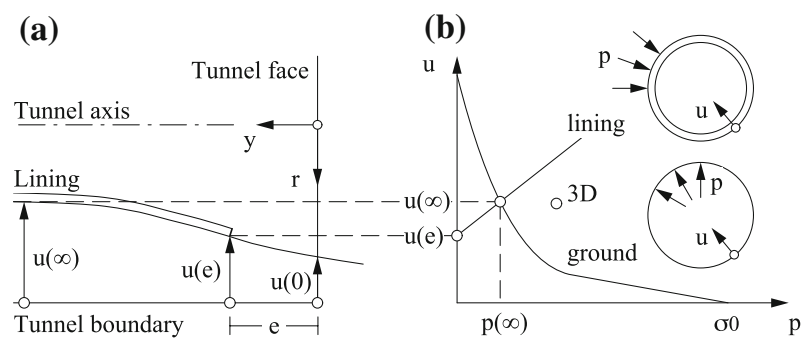

Fig. 1 a Radial displacement of the tunnel wall. b Characteristic lines of the ground and of the lining 
of the two lines (the "ground response point") fulfils the conditions of equilibrium and compatibility, and shows the radial pressure $p(\infty)$ acting upon the lining far behind the face and the respective radial displacement $u(\infty)$ of the ground at the excavation boundary $r=a$. For determining the intersection point, an a priori assumption must be made concerning the ground displacement $u(e)$ that occurs before the lining is installed ("pre-deformation"). Note that small variations in the assumed pre-deformation $u(e)$ may lead to large variations in rock pressure, particularly in the case of a highly non-linear ground response. This sensitivity has prompted considerable research aimed at finding methods for estimating predeformation without needing to carry out costly spatial numerical analyses. Research efforts in the 1990s were focused mainly on the axisymmetric problem of a cylindrical tunnel (Corbetta 1990; Bernaud 1991; Bernaud and Rousset 1996; Nguyen-Minh and Corbetta 1992; Nguyen-Minh and Guo 1993, 1996; Guo 1995; Panet 1995; AFTES 2002), while recent papers have examined the influence of the tunnel shape and of the anisotropy or heterogeneity of the initial stress field (Carranza-Torres and Fairhurst 2000; González-Nicieza et al. 2008).

The problem is, however, more fundamental than estimating the magnitude of pre-deformation: for geomaterials with path-dependent mechanical behavior, the existence of a single "ground response curve" is, in itself, questionable, as the response of the ground depends on its stress history and, in the case of timedependent processes, such as creep (Kaiser 1980) or consolidation (Anagnostou 2007a), on the excavation advance rate as well. The method involving characteristic lines may, nevertheless, oversimplify reality, even in the absence of timedependency. So, for example, Amberg (1999) has remarked (on the basis of the results of design calculations for the Gotthard Base Tunnel) that three-dimensional simulations of tunnel excavation may lead to both higher ground pressures and higher deformations than those predicted by plane strain calculations (i.e., to ground response points which are located above the ground response curve, e.g., point "3D" in Fig. 1b). Also, Bliem (2001) and Kumasaka (2007) recognized that the final lining pressure and the final ground deformation obtained by a spatial calculation may be higher than the values obtained by considering the ground response curve. Furthermore, the numerical results presented by Barla $(2000,2001)$ show a significant difference between the stresses predicted by two- and threedimensional models, with a clear influence on the stress path experienced by the ground surrounding the tunnel. The role of the stress path has also been examined in recent years in the context of tunneling or mining through hard brittle rocks (Pelli et al. 1995; Martin et al. 1999; Cai et al. 2002; Diederichs et al. 2004a, b). So, for example, Eberhardt (2001) presented the results of a three-dimensional numerical study on the rotation of the principal stress axes in the vicinity of the tunnel face and on its effect on the direction of fracture propagation.

In the present paper, emphasis is placed on the influence of the stress path on the deformations and ground pressures developing in tunnels crossing weak rocks that are prone to squeezing and exhibit important plastic flow. More specifically, it is the purpose of this paper to show, by comparative computations, how greatly the ground response calculated using a more realistic spatial model may deviate from the response predicted through plane strain analyses (Sect. 3), to show the 
limitations and the nature of the simplifications involved in even the most sophisticated methods of pre-deformation estimation (Sect. 4), and to improve our understanding of the reasons for these deviations (Sect. 5).

The present investigation concerns only the effect of the computational domain (plane vs. spatial system). It should be noted, however, that the stress history of the ground and its response to tunneling may also be influenced by time-effects. The latter are particularly pronounced when the ground becomes overstressed and are, therefore, important for squeezing behavior. This aspect is not dealt with by the present paper.

\section{Problem Layout and Solution Method}

\subsection{Problem Layout}

For the sake of simplicity and without compromising its general applicability, the comparative analyses of the present paper refer to a deep, cylindrical, and uniformly supported tunnel that crosses a homogeneous and isotropic ground. The initial stress field is assumed to be uniform and hydrostatic. The mechanical behavior of the ground is modeled as isotropic, linearly elastic, and perfectly plastic according to the Mohr-Coulomb yield criterion with a non-associated flow rule.

The lining is modeled as an elastic radial support with stiffness $k=\mathrm{d} p / \mathrm{d} u$, where $p$ and $u$ denote the radial loading and the radial displacement of the lining, respectively. The radial stiffness $k$ of a ring-shaped lining is equal to $E_{\mathrm{L}} d / a^{2}$, where $a, d$, and $E_{\mathrm{L}}$ denote its radius, thickness, and Young's modulus, respectively. The longitudinal bending stiffness of the lining will not be taken into account. (This effect is, however, of subordinate importance.) Lining installation occurs at a distance $e$ behind the tunnel face (Fig. 1a).

Under the assumptions made above, the problem obeys rotational symmetry with respect to the tunnel axis $y$ (Fig. 1a). The plane strain assumption leads to a onedimensional problem, for which closed-form solutions exist (Sect. 2.2), while the three-dimensional problem of the advancing tunnel heading reduces, then, to a twodimensional axisymmetric problem that is solved numerically by the finite element method (Sect. 2.3).

\subsection{Plane Strain Problem}

According to the closed-form solutions presented by, e.g., Anagnostou and Kovári (1993), the displacements in the elastic range, i.e., if:

$$
\frac{\bar{p}}{\bar{\sigma}_{0}} \geq \frac{2}{m+1},
$$

are given by the following equation:

$$
u(p)=\frac{a \bar{\sigma}_{0}}{E}(1+v)\left(1-\frac{\bar{p}}{\bar{\sigma}_{0}}\right)
$$

while in the elasto-plastic range: 


$$
u(p)=\frac{\overline{a \sigma_{0}}}{E}\left(\delta_{1}+\delta_{2} \frac{\bar{p}}{\bar{\sigma}_{0}}+\delta_{3}\left(\frac{\bar{p}}{\bar{\sigma}_{0}}\right)^{-\delta_{4}}\right)
$$

where:

$$
\begin{aligned}
\bar{p} & =p+\frac{f_{c}}{m-1}, \quad \bar{\sigma}_{0}=\sigma_{0}+\frac{f_{c}}{m-1}, \quad m=\frac{1+\sin \Phi}{1-\sin \Phi}, \quad \kappa=\frac{1+\sin \Psi}{1-\sin \Psi}, \\
\delta_{1} & =-(1-2 v)(1+v), \quad \delta_{2}=(1+v) \frac{(1-v)(1+m \kappa)-v(m+\kappa)}{m+\kappa}, \\
\delta_{3} & =\frac{2\left(1-v^{2}\right)(m-1)}{m+k}\left(\frac{2}{m+1}\right)^{\delta_{4}}, \quad \delta_{4}=\frac{\kappa+1}{m-1} .
\end{aligned}
$$

These equations assume that plastic flow takes place only in the plane of the tunnel cross section. According to the adopted Coulomb yield criterion, this is true only if the secondary axial stress is the strict intermediate principal stress. The effect of the axial stress on the deformation fields around a cylindrical cavity in a brittle Coulomb material has been investigated analytically by Nguyen-Minh and Berest (1979) and Reed (1988). Here, attention is paid to the special case of a perfectly plastic material. The closed-form solution for the stress field and the ground response curve is given in the Appendix. According to this analysis, when the support pressure is low and the initial stress is high, outof-plane plastic strains develop as both the axial stress and the tangential stress fulfill the yield condition (so-called "edge flow"). The error introduced by neglecting the out-of-plane plastic strains may be considerable for materials exhibiting softening behavior (Reed 1988), but, as shown below, is negligible for perfectly plastic materials.

Figure 2 a shows ground response curves for an example with parameter values according to Table 1 (with $c=500 \mathrm{kPa}$ ). The dashed curve is based upon Eq. 3, which does not take into account the out-of-plane plastic flow, while the solid line has been calculated by the closed-form solution derived in the Appendix (Eq. A31). The marked points have been obtained numerically by the finite element method. (In the numerical calculations, edge flow is taken into account based upon the classical method of Koiter 1953.) The error caused by neglecting the out-of-plane strains is, in this example, negligible. In the theoretical case of $v=0$, the error is larger but still small (Fig. 2b). The numerical solutions agree well with the analytical ones. Figure 3 provides a more complete picture. The diagram shows the error over the normalized support pressure for a friction angle $\phi=15$ or $35^{\circ}$, the common range of Poisson's ratio $(v=0.15-0.35)$ and the two borderline cases of the flow rule $\left(\psi=0^{\circ}\right.$ or $\left.\phi\right)$. As can be seen from Fig. 3, neglecting the plastic flow in the axial direction leads, in general, to an underestimation of the radial boundary displacement by a few percent.

\subsection{Axisymmetric Problem}

The numerical solution of the axisymmetric problem is usually based upon a simulation of the excavation and support installation that models the advancing 
(a) $v=0.3$

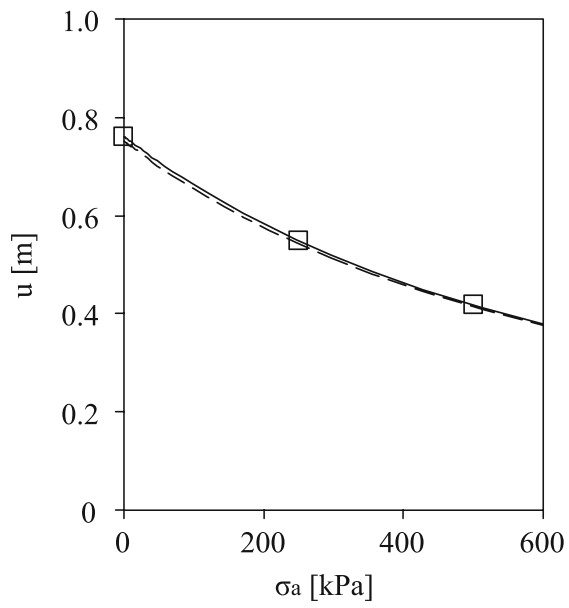

(b) $v=0.0$

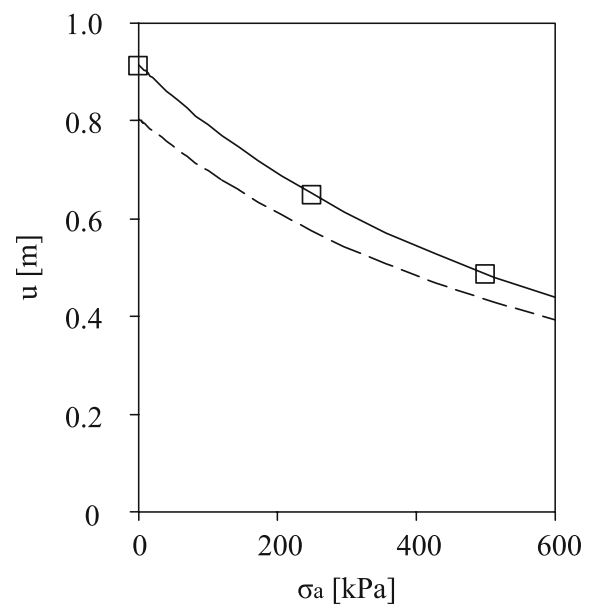

Analytically with consideration of out-of-plane flow

- - - Analytically without consideration of out-of-plane flow

$\square \quad$ Numerically

Fig. 2 Ground response curve with/without consideration of out-of-plane plastic flow (solid/dashed curve, respectively), as well as numerically obtained results (marked points). a Poisson's ratio $v=0.30$. b Poisson's ratio $v=0.0(c=500 \mathrm{kPa}$; other parameters, see Table 1$)$

Table 1 Assumed model parameters

\begin{tabular}{ll}
\hline Parameter & Value \\
\hline Initial stress, $\sigma_{0}$ & $12.5 \mathrm{MPa}$ \\
Tunnel radius, $a$ & $4 \mathrm{~m}$ \\
Lining stiffness, $k$ & Variable \\
Unsupported span, $e$ & Variable \\
Young's modulus (ground), $E$ & $1,000 \mathrm{MPa}$ \\
Poisson's ratio (ground), $v$ & 0.3 \\
Angle of internal friction (ground), $\varphi$ & $25^{\circ}$ \\
Cohesion (ground), $c$ & 500 or $2,000 \mathrm{kPa}$ \\
Dilatancy angle (ground), $\psi$ & $5^{\circ}$ \\
\hline
\end{tabular}

tunnel heading step-by-step (see, e.g., Franzius and Potts 2005). Since large stress and deformation gradients prevail in the vicinity of the tunnel face and the latter moves during the step-by-step simulation, either the finite element mesh has to be fine everywhere along the tunnel axis or adaptive re-meshing must be carried out for each excavation step. Such an analysis is, therefore, very time-consuming, even in the case of linear material behavior. 

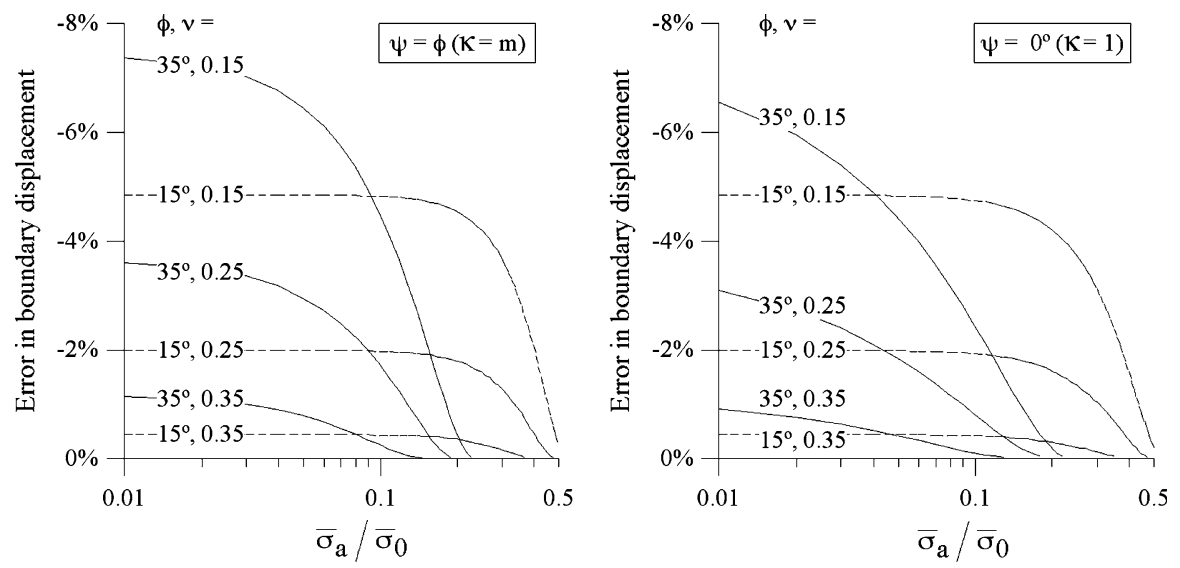

Fig. 3 Error caused by not considering the out-of-plane plastic flow

The present problem, however, belongs to the large category of problems with constant conditions in the tunneling direction (the stress and deformation fields are steady with respect to the tunnel heading, i.e., they "advance" together with the face in the direction of excavation) and it is solved here by means of a single computational step. The basic principle behind this so-called one-step solution method can be traced back to the work of Nguyen-Quoc and Rahimian (1981) on steady crack propagation in elasto-plastic media, and it is that the time coordinate can be eliminated from the equations governing the steady state by re-formulating the equations in a frame of reference that is fixed to the advancing heading. In such an approach, the co-ordinate $y$ in the tunneling direction (Fig. 1a) undertakes the role of the time dimension in the integration of the elasto-plastic constitutive equations. Corbetta (1990) applied this method for the analysis of advancing tunnels in elasto-plastic and viscoplastic media (see also Corbetta and NguyenMinh 1992), while Anagnostou (2007a) proposed a generalization of the one-step solution method for coupled problems involving seepage flow and consolidation processes. Details concerning the calculation of the internal forces of the support elements (under consideration of the pre-deformations of the ground) can be found in Anagnostou (2007b).

Figures 4 and 5 compare numerical results obtained by the one-step solution method with the results of step-by-step computations. A sequential excavation and support installation procedure is determined by the following two geometrical parameters: the round length $s$ and the minimum distance $e$ between the leading edge of the support and the tunnel face (Fig. 4a). In the step-by-step method, the excavation and support cycles are simulated by activating support elements and deactivating ground elements stepwise over successive round lengths $s$. Each excavation round causes a stress re-distribution in the longitudinal direction and an additional load increment upon the installed support elements. The anterior parts of the support elements are more affected by the excavation of the core, because the effect of each excavation round decreases with the distance from the face. This leads 
(a)

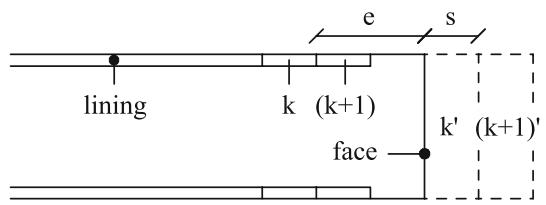

\section{calculation steps:}

lining istallation $\mathrm{k}$

calculation for excavation $\mathrm{k}^{\prime}$

lining istallation $(\mathrm{k}+1)$

calculation for excavation $(\mathrm{k}+1)^{\prime}$

(b)

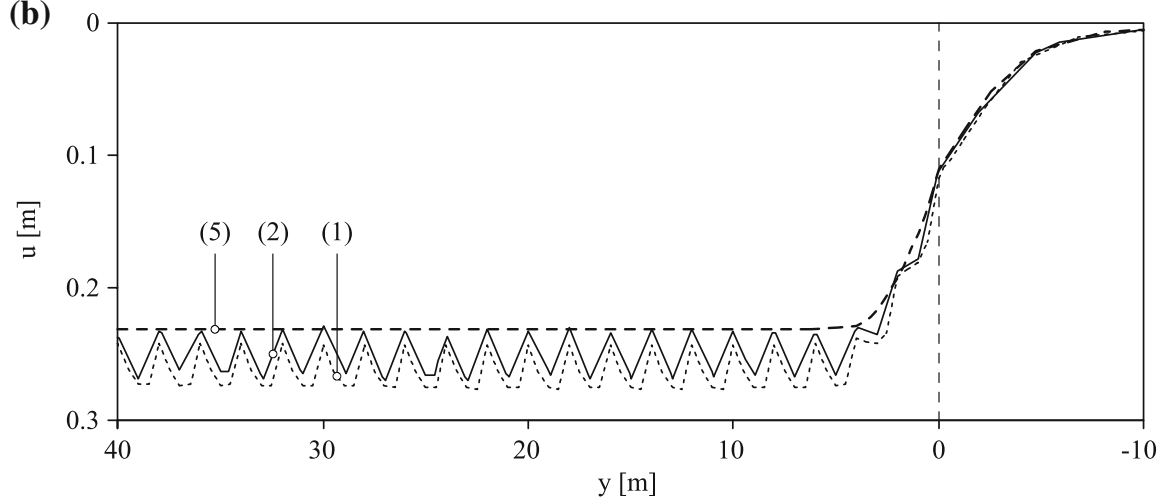

(c)

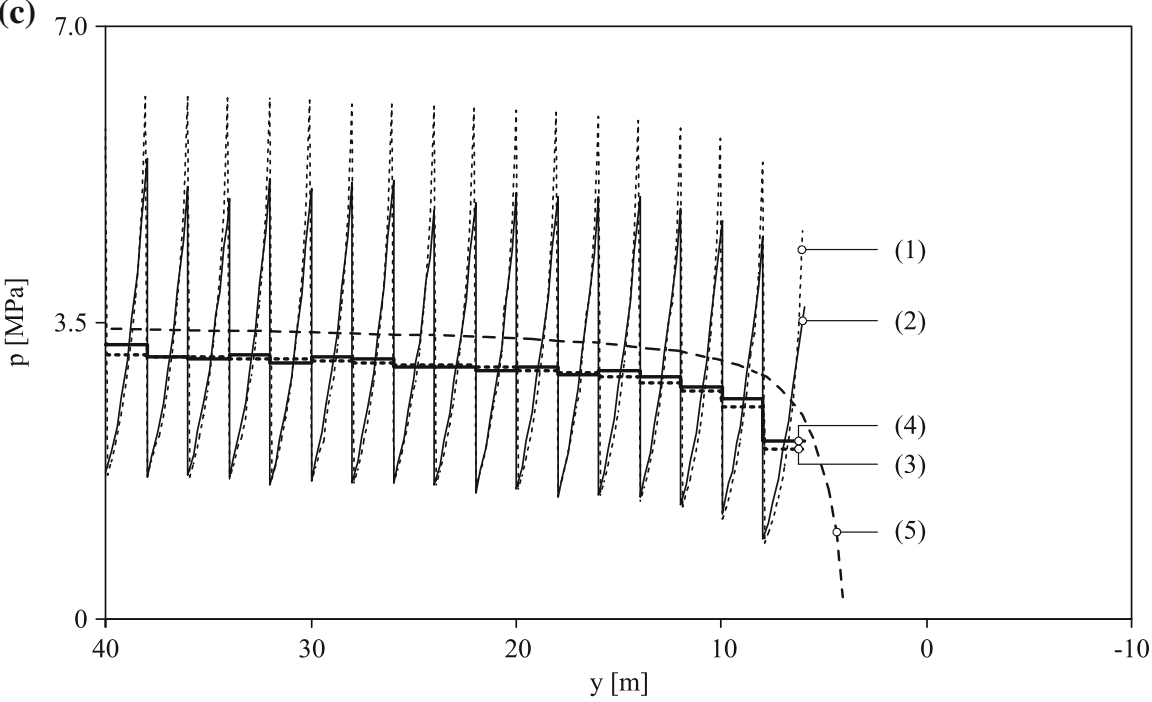

(1) step-by-step calculation with HYDMEC

(2) step-by-step calculation with PLAXIS

(3) step-by-step calculation with HYDMEC, average pressure

(4) step-by-step calculation with PLAXIS, average pressure

- - - (5) one-step solution method with HYDMEC

Fig. 4 a Calculation sequence in the step-by-step method. b Radial displacement of the tunnel boundary. c Distribution of the pressure acting upon the lining 
to a saw-shaped distribution of the ground pressure and deformation along the tunnel wall. Lines 1 and 2 in Fig. 4 have been obtained by means of step-by-step simulations performed by the finite element code HYDMEC of the ETH Zurich (Anagnostou 1992) and the commercial geotechnical finite element package PLAXIS (Brinkgreve 2002), respectively. The parameters of the numerical example are: round length $s=2 \mathrm{~m}$, unsupported span $e=4 \mathrm{~m}$, cohesion $c=500 \mathrm{kPa}$, lining thickness $d=50 \mathrm{~cm}$, Young's modulus of the lining $E_{\mathrm{L}}=30 \mathrm{GPa}$ (see Table 1 for the other parameters). The lining was modeled as an elastic radial support with (PLAXIS simulation) or without (HYDMEC simulation) longitudinal bending stiffness. The saw-shaped distribution is typical for step-by-step simulations (see, e.g., Bonnier et al. 2002; Graziani et al. 2005) and, as can be seen from Fig. 4, occurs even if taking into account the bending stiffness of the support. Furthermore, the comparison of lines 1 and 2 in Fig. 4 shows that the simplification
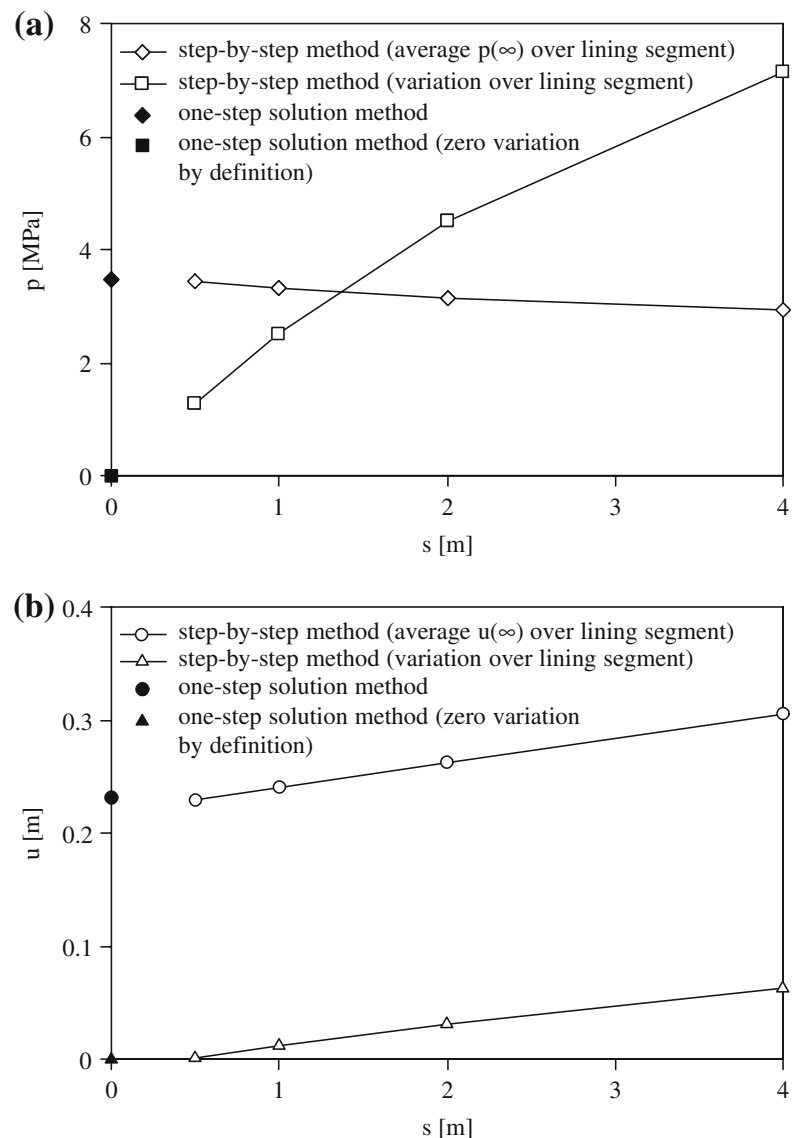

Fig. 5 Results of the step-by-step method as a function of round length $s$ and results of the one-step solution method (plotted at $s=0$ ) for an unsupported span $e=4 \mathrm{~m}$ 
introduced by neglecting the longitudinal bending stiffness of the lining is not decisive for the investigation of the final lining pressures and convergences.

Line 5 in Fig. 4 show the respective numerical results of the one-step solution method implemented in the finite element code HYDMEC. The distribution of the pressures and deformations along the tunnel is smooth because the round length does not represent a parameter in this method. In fact, the one-step solution method refers to the borderline case of a zero round length $s$. The length of the unsupported span is, thus, continuously equal to $e$, while in the step-by-step simulations, it varies between $e$ and $e+s$ (Fig. 4a). Due to the shorter unsupported span, the one-step solution method leads to slightly lower ground deformations and slightly higher ground pressures. (For the comparison of the pressures, the numerical results of the step-by-step simulations have been averaged over each lining segment; see lines 3 and 4 in Fig. 4c).

For the validation of the implementation of the one-step solution method into the finite element code HYDMEC, a series of step-by-step simulations has been carried out with different values of the round length $s$. The lines marked by white symbols in Fig. 5 show the influence of the round length $s$ on the final lining pressure $p$ and ground deformation $u$ (average values and variation over the lining segment). One recognizes that the results of the step-by-step calculations approach the values obtained by the one-step solution method (black markers) with decreasing round length. The one-step solution method corresponds, thus, to the limiting case of a step-by-step model with zero round length.

\section{Deviation from the Plane Strain Response}

In this section, the results of plane strain analyses will be compared to those of spatial analyses that take into account the advance of the tunnel heading. The analysis refers to a 500-m deep tunnel that has a radius $a=4 \mathrm{~m}$. Table 1 summarizes the parameters of the model. The material constants (particularly, the low dilatancy angle) are typical for the weak kakiritic rocks from the Gotthard Base Tunnel (Vogelhuber et al. 2004). Concerning the shear strength of the ground, two cohesion values have been considered. The higher value $(c=2,000 \mathrm{kPa})$ applies to a moderately squeezing ground, the lower $(c=500 \mathrm{kPa})$ to a heavily squeezing ground.

Typical linings have a stiffness $k$ in the range $0.1-1 \mathrm{GPa} / \mathrm{m}$. The calculations have been carried out for a wider range of stiffness values $(0.01-100 \mathrm{GPa} / \mathrm{m})$ in order to gain a complete picture of model behavior. Furthermore, unsupported spans $e$ of up to $16 \mathrm{~m}$ have been considered. The larger values for an unsupported span take into account, in a simplified way, the case of a yielding support that allows the occurrence of a free radial convergence $[u(0)-u(e)$ in Fig. 1a] and starts to exert a pressure at a distance $y=e$ behind the tunnel face.

Figure $6 \mathrm{~b}$ shows the ground response curve (the solid line marked by "GRC") obtained by a closed-form, plane strain solution (Eq. 3), as well as the results of the numerical calculations for the case of heavily squeezing ground (points marked by circles, e.g., $A_{1,2,3, \ldots}$; see also Table 2 ). The numerical results show that the ground 

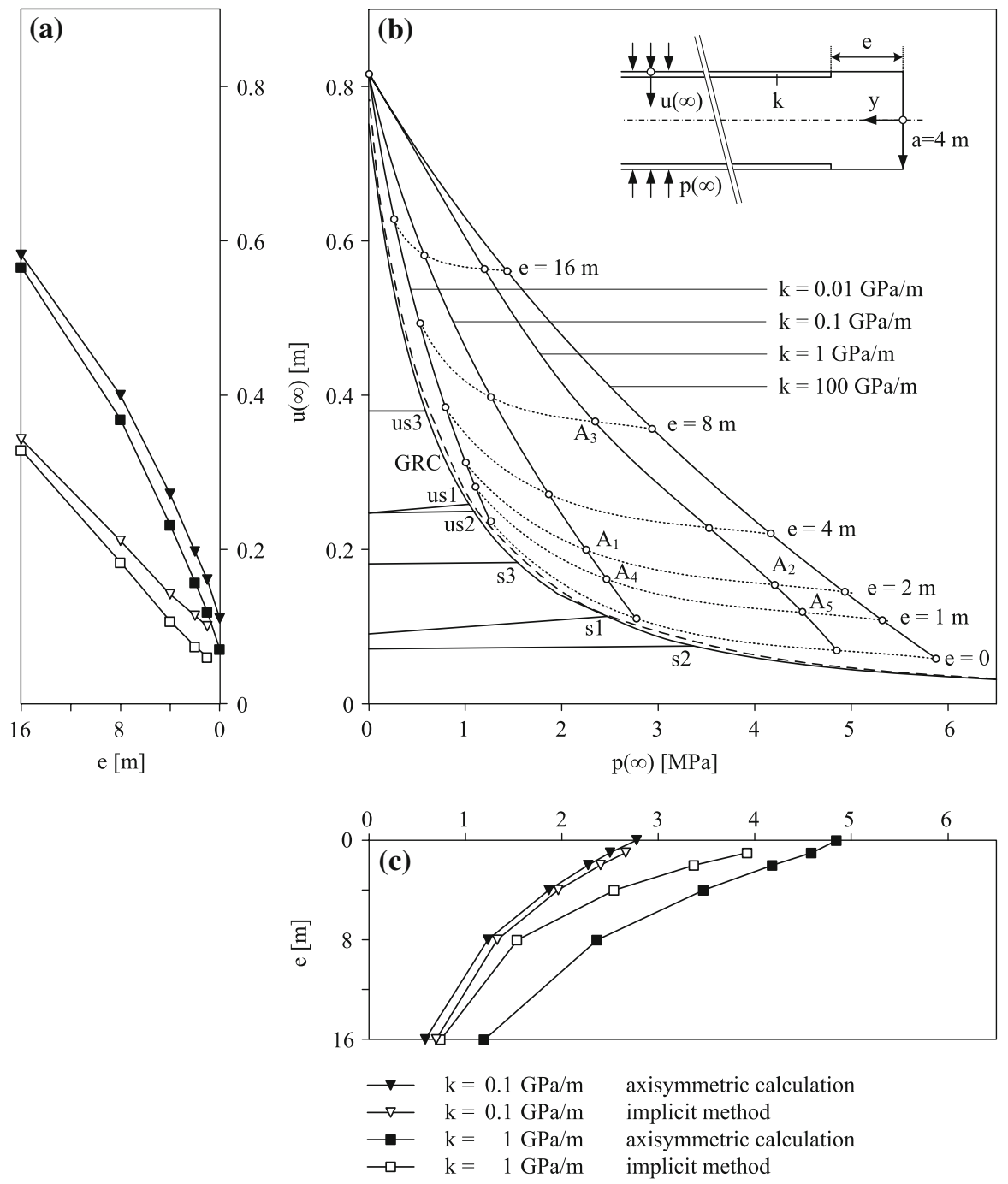

Fig. 6 Heavily squeezing ground. a Radial displacement $u(\infty)$ of the ground far behind the face as a function of the unsupported span $e$. b Ground response curve under plane strain conditions $(G R C)$, ground response curve under axisymmetric conditions for the case of a uniform support pressure acting along the

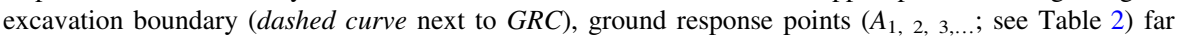
behind the tunnel face (at $y / a=75$ ) for different unsupported spans $e$ and lining stiffnesses $k$, characteristic lines of support ( $u s 1, u s 2, u s 3, s 1, s 2, s 3$; see Table 2). c Radial pressure $p(\infty)$ acting upon the lining far behind the face as a function of the unsupported span $e$

response deviates considerably from the plane strain curve $(G R C)$. The stiffer the lining and the longer the unsupported span $e$, the more pronounced will be the difference. Plane strain analysis systematically underestimates ground pressures and deformations. The same observation, but to a lesser degree, can be made for the case 
Table 2 Parameters for support and ground response points in Figs. 6 and 7

\begin{tabular}{llll}
\hline Line or point & $k(\mathrm{GPa} / \mathrm{m})$ & $e(\mathrm{~m})$ & Estimation of pre-deformation \\
\hline$u s 1$ & 0.1 & 2 & Based upon unsupported opening (Eq. 10) \\
$u s 2$ & 1 & 2 & \\
$u s 3$ & 1 & 8 & \\
$s 1$ & 0.1 & 2 & Implicit method (Eqs. 13 and 14) \\
$s 2$ & 1 & 2 & \\
$s 3$ & 1 & 8 & \\
$A_{1}$ & 0.1 & 2 & \\
$A_{2}$ & 1 & 2 & \\
$A_{3}$ & 1 & 8 & \\
$A_{4}$ & 0.1 & 1 & \\
$A_{5}$ & 1 & 1 & \\
\hline
\end{tabular}

of a moderately squeezing ground (Fig. 7b). The underestimation of ground pressures and deformations by the plane strain model is typical for elasto-plastic ground behavior. For elastic behavior, of course, there is no difference between the plane and the spatial model.

A plane strain analysis is adequate under the following conditions:

(i) It must lead to ground response points $(p(\infty), u(\infty))$ that are close to the ones obtained when taking into account the evolution of stress and deformation in the vicinity of the working face.

(ii) A practicable way exists to estimate the pre-deformations of the ground, i.e., the deformations that take place up to the installation of the support.

As can be seen from Figs. $6 b$ and $7 b$, the first condition is fulfilled in the case of a lower stiffness lining (low $k$ values) or a lining installation close to the face (small $e$ values). With respect to the second condition, the ground pressure and deformation values obtained by the convergence-confinement method will be examined next.

\section{Limitations of the Convergence-Confinement Method}

The estimation of pre-deformation, which is of paramount importance for any plane strain model, starts by considering the development of the radial displacement $\bar{u}_{\mathrm{E}}(y)$ along the excavation boundary $(y>0, r=a)$ of an unsupported tunnel crossing a linearly elastic ground:

$$
\bar{u}_{\mathrm{E}}(y)=\bar{u}_{\mathrm{E}}(\infty) F\left(\frac{y}{a}\right),
$$



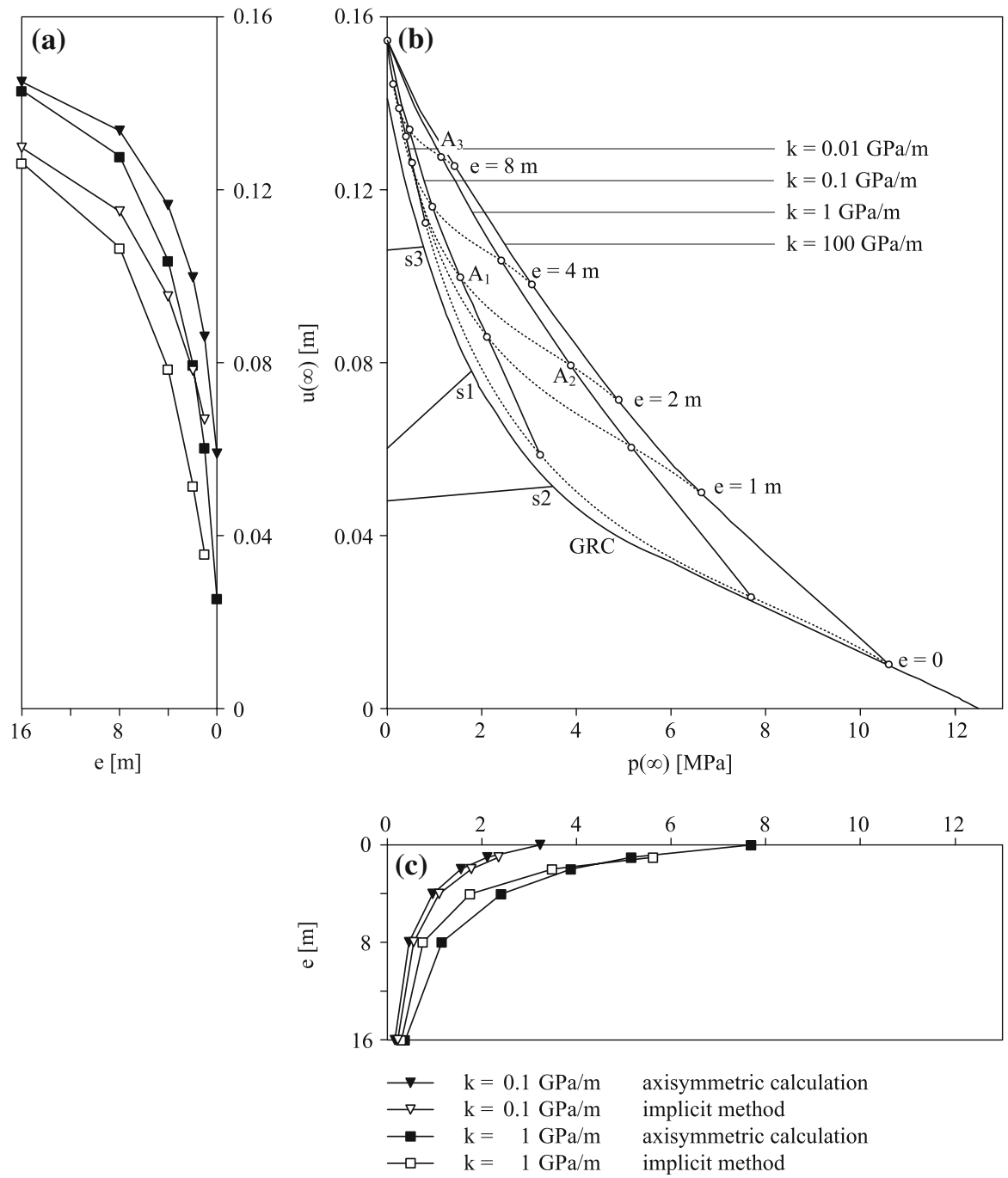

Fig. 7 Moderately squeezing ground. a Radial displacement $u(\infty)$ of the ground far behind the face as a function of the unsupported span $e$. b Ground response curve under plane strain conditions $(G R C)$, ground response points $\left(A_{1,2,3, \ldots}\right.$; see Table 2$)$ far behind the tunnel face (at $\left.y / a=75\right)$ for different unsupported spans $e$ and lining stiffnesses $k$, characteristic lines of support ( $s 1, s 2, s 3$; see Table 2). c Radial pressure $p(\infty)$ acting upon the lining far behind the face as a function of the unsupported span $e$

where $\bar{u}_{\mathrm{E}}(\infty)$ denotes the final radial displacement far behind the face (given by Eq. 3 with $p=0$ ), while the function $F$ is defined as follows (AFTES 2002):

$$
F(t):=1-0.75\left(\frac{0.75}{0.75+t}\right)^{2}
$$




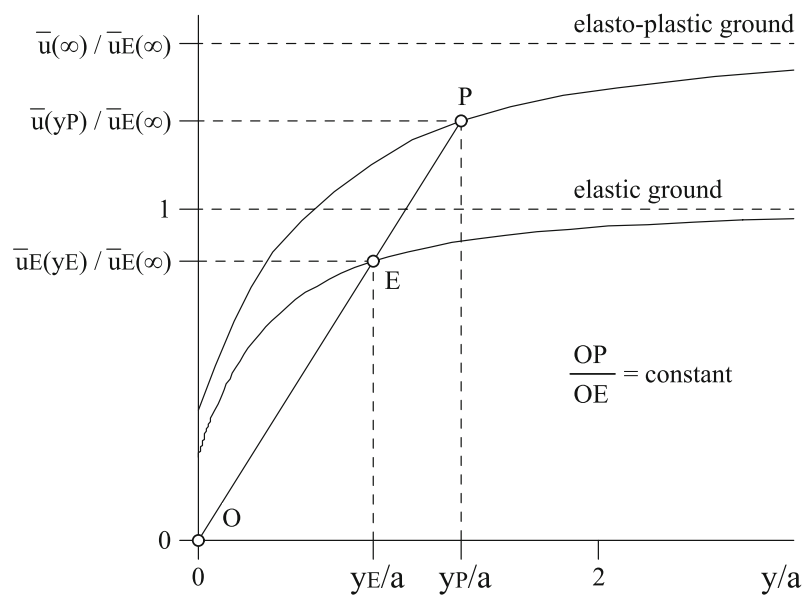

Fig. 8 Development of radial displacement along the excavation boundary of an unsupported tunnel crossing an elasto-plastic ground according to Corbetta (1990)

or, according to Corbetta (1990):

$$
F(t):=0.29+0.71\left(1-\exp \left(-1.5 t^{0.7}\right)\right) .
$$

As both expressions lead to similar results, Eq. 6 will be used in the comparative calculations of the present paper. Following Corbetta (1990), the development of convergence $\bar{u}(y)$ for the case of elasto-plastic ground can be obtained approximately by applying a so-called homothetic transformation to the elastic convergence $\bar{u}_{\mathrm{E}}(y)$ (Fig. 8):

$$
\frac{O P}{O E}=\frac{\bar{u}(\infty)}{\bar{u}_{\mathrm{E}}(\infty)}=\mathrm{constant},
$$

where $\bar{u}(\infty)$ denotes the final elasto-plastic convergence of an unsupported tunnel (given by Eq. 2 with $p=0$ ). It follows from Eqs. 2, 3, and 8 that the so-called similitude ratio $\bar{u}(\infty) / \bar{u}_{\mathrm{E}}(\infty)$ depends on the initial stress $\sigma_{0}$, on the Poisson's ratio $v$, and on the plasticity constants $c, \phi$, and $\psi$. From Fig. 8 , it follows that:

$$
\bar{u}\left(y_{\mathrm{P}}\right)=\frac{\bar{u}(\infty)}{\bar{u}_{\mathrm{E}}(\infty)} \bar{u}_{\mathrm{E}}\left(y_{\mathrm{E}}\right) ; \quad y_{\mathrm{E}}=\frac{\bar{u}_{\mathrm{E}}(\infty)}{\bar{u}(\infty)} y_{\mathrm{P}} .
$$

Equations 5 and 9 yield, with $y_{\mathrm{P}}=e$, the convergence at the point of support installation:

$$
\bar{u}(e)=\bar{u}(\infty) F\left(\frac{\bar{u}_{\mathrm{E}}(\infty)}{\bar{u}(\infty)} \frac{e}{a}\right) .
$$

Equation 10 offers the simplest way of estimating pre-deformation, but, at the same time, it leads, as pointed out by the AFTES (2002), to a serious underestimation of ground pressure. This can be illustrated by comparing the numerical results of Figure $6 \mathrm{~b}$ with the results obtained by the convergence-confinement method. The straight lines $u s 1, u s 2$, and $u s 3$ are the characteristic lines for three linings with 
different stiffnesses $k$ and an unsupported span $e$ (Table 2). Line $u s 1$ applies to a rather soft lining $(k=0.1 \mathrm{GPa} / \mathrm{m}$, i.e., a $15-\mathrm{cm}$ thick ring with a Young's modulus of only $10 \mathrm{GPa}$ ) installed at $e=2 \mathrm{~m}$ behind the face. The intersection point of the line $u s 1$ with the ground response curve gives the ground pressure and deformation according to the convergence-confinement method. It is lower-by a factor of 2than the pressure obtained by the axisymmetric analysis (point $A_{1}$ ). Lines us 2 and us3 apply to a higher lining stiffness $(k=1 \mathrm{GPa} / \mathrm{m}$, i.e., a 50-cm thick ring with a Young's modulus of $30 \mathrm{GPa}$ ) and an unsupported span $e$ of 2 or $8 \mathrm{~m}$, respectively. Points $A_{2}$ and $A_{3}$ mark the respective results of the axisymmetric analysis. Here, the convergence-confinement method underestimates the pressure by a factor of about 4.

As Eq. 10 is based upon the development of convergence along an unsupported opening, while a stiff lining reduces not only the final convergence but the predeformations as well, the underestimation of pressure by the convergenceconfinement method has been attributed to the overestimation of pre-deformation (see, e.g., AFTES 2002). We see, however, from Fig. 6b that the deformations are actually only slightly overestimated. The fact that all of the ground response points $A_{1,2}, 3, \ldots$ are located above the plane strain ground response curve shows that the problem is more fundamental: a plane strain analysis cannot reproduce both the deformations and the pressures. In order to determine the ground pressure through a plane strain analysis, the pre-deformations have to be underestimated.

A more advanced, so-called implicit method (Guo 1995; Nguyen-Minh and Guo 1996) attempts to resolve this problem basically by applying a reduction factor $\Phi$ to the "unsupported" pre-deformation $\bar{u}(e)$ :

$$
u(e)=\Phi\left(\frac{u(\infty)}{\bar{u}(\infty)}\right) \bar{u}(e),
$$

where $u(e)$ and $u(\infty)$ denote the pre-deformation and final convergence of the supported opening, respectively, while the function $\Phi$ is defined as follows:

$$
\Phi(t):=0.55+0.45 t-0.42(1-t)^{3} .
$$

Equations 10 and 12 lead to the following expression for the pre-deformation:

$$
u(e)=\bar{u}(\infty) F\left(\frac{\bar{u}_{\mathrm{E}}(\infty)}{\bar{u}(\infty)} \frac{e}{a}\right) \Phi\left(\frac{u(\infty)}{\bar{u}(\infty)}\right) .
$$

According to Eq. 13, the pre-deformation $u(e)$ depends on the final displacement $u(\infty)$ and, thus, (see Eq. 2) on the unknown final support pressure $p(\infty)$ as well. The latter is, however, related to the deformation of the support:

$$
p(\infty)=k(u(\infty)-u(e)) .
$$

Equations 13 and 14 form a system for the support pressure $p(\infty)$ and the predeformation $u(\mathrm{e})$. By inserting $u(\mathrm{e})$ from Eq. 13 into 14, we obtain a non-linear equation for the support pressure $p(\infty)$, which can be easily solved using Newton's iteration method.

The pre-deformations underlying the characteristic lines of supports $s 1, s 2$, and $s 3$ in Fig. $6 \mathrm{~b}$ have been calculated in this way. Line $s 1$ applies to a soft lining 
( $k=0.1 \mathrm{GPa} / \mathrm{m}$ ) installed at $e=2 \mathrm{~m}$ behind the face. The intersection point of the characteristic line $s 1$ with the ground response curve is located below the respective ground response point $A_{1}$, i.e., it shows a practically equal ground pressure but underestimates the radial displacement. At a higher lining stiffness (lines $s 2$ and $s 3$ ), both the ground pressure and the pre-deformation are underestimated considerably (by $1 \mathrm{MPa}$ and 15-20 cm, respectively, compared with points $A_{2}$ and $A_{3}$ ). In order to achieve a better agreement with the numerically obtained ground pressure value, an even smaller and unrealistic pre-deformation must be assumed. Note that, due to the large $\mathrm{d} p / \mathrm{d} u$ gradient of the plane strain ground response curve in the relevant pressure range, small variations in the assumed pre-deformation lead to significant variations in the ground pressure.

Figure 6a, c provide a more complete picture of the differences between the results of the convergence-confinement method and the axisymmetric analyses. The diagrams show the ground pressure $p$ and the ground displacement $u$, respectively, as a function of the length $e$ of unsupported span for two values of lining stiffness: a soft lining $(k=0.1 \mathrm{GPa} / \mathrm{m}$, e.g., a $15-\mathrm{cm}$ thick ring with a Young's modulus of only $10 \mathrm{GPa})$ and a rather stiff lining $(k=1 \mathrm{GPa} / \mathrm{m}$, e.g., a $50-\mathrm{cm}$ thick ring with a Young's modulus of $30 \mathrm{GPa}$ ). According to Fig. 6c, the ground pressures predicted by the implicit method for the soft lining agree well with the numerical results for all $e$ values, while the deformations are underestimated by a factor of 1.5-2, particularly for long unsupported spans (Fig. 6a). For the stiff lining, however, the pressures are underestimated considerably (up to $1 \mathrm{MPa}$ ). A similar trend can also be observed for the moderately squeezing ground (Fig. 7). It is, however, remarkable that the results of the convergence-confinement method here agree better with the ones of the axisymmetric analyses.

On the basis of these comparisons, it can be concluded that the convergenceconfinement method, even in combination with advanced methods of predeformation estimation, underestimates the ground pressure and deformation, particularly for stiff linings, long unsupported spans, and heavily squeezing ground with highly non-linear material behavior.

\section{Stress and Deformation History and its Effect on Ground Response}

Next, the numerical results obtained for the case of the heavily squeezing ground will be studied in detail in order to explain the reasons for the deviation of the ground response values from those that were predicted under plane strain conditions.

\subsection{Stresses and Deformations}

Figure 9 shows the region with plastic deformations and the stress distribution along the excavation boundary ( $r=a$ ) for an unsupported opening (Fig. 9a), as well as for three supported tunnels with a different lining stiffness $k$ and unsupported spans $e$ (Fig. 9b-d). The term "past yield zone" will be explained later in this section. As can be seen from Fig. 9, the axial stress $\sigma_{y y}$ ahead of the face decreases with the 

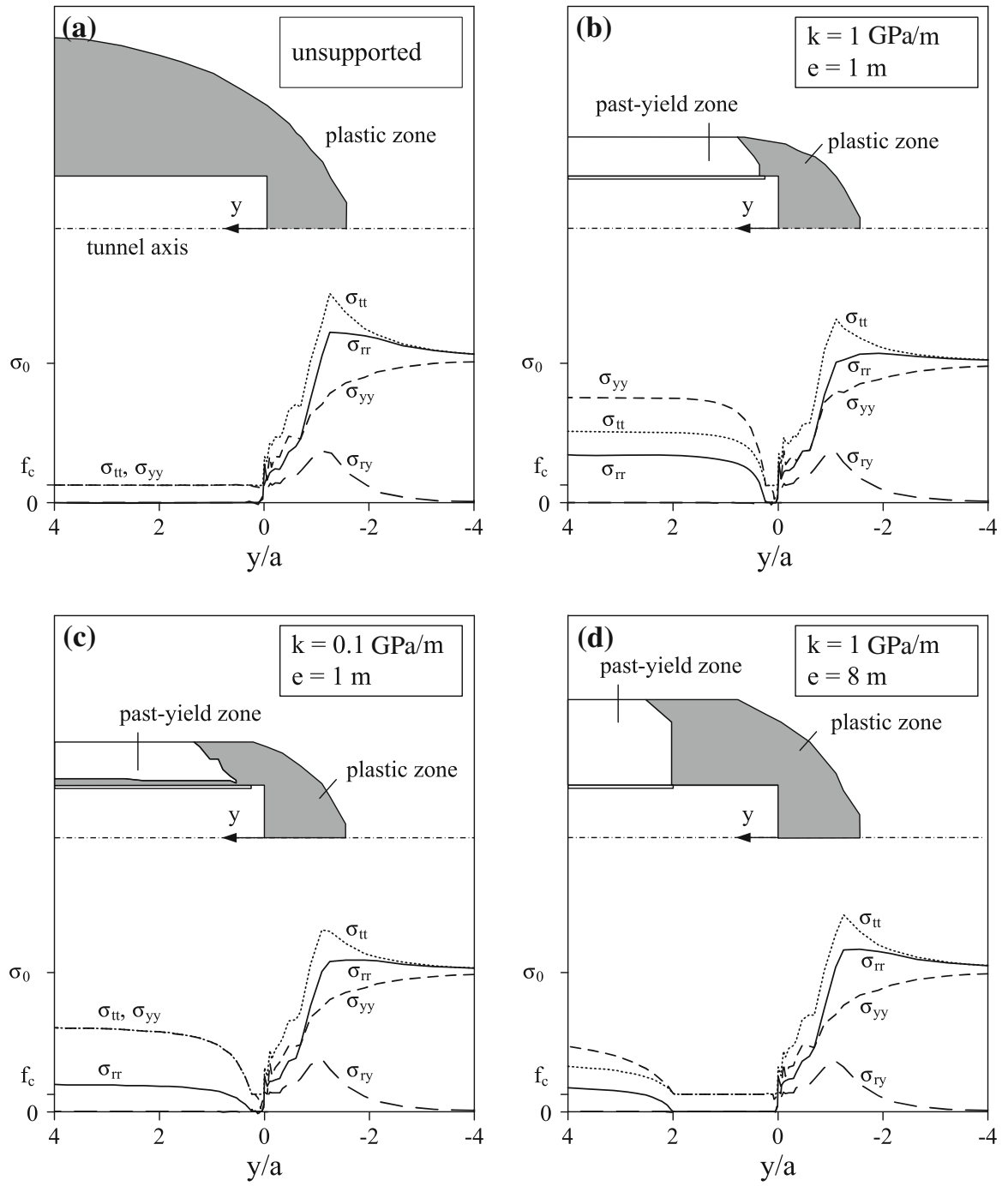

Fig. 9 Plastic zone and history of the radial $\left(\sigma_{r r}\right)$, tangential $\left(\sigma_{t t}\right)$, axial $\left(\sigma_{y y}\right)$, and shear stress $\left(\sigma_{r y}\right)$ along the tunnel boundary $(r=a)$. Note that the cases $\mathbf{b}$, $\mathbf{c}$, and $\mathbf{d}$ correspond to the points $A_{5}, A_{4}$, and $A_{3}$ of Fig. 6b, respectively

approaching excavation from its initial value $\sigma_{0}$ (which prevails far ahead of the face) to zero (at the unsupported tunnel face). Due to the lowered axial stress, the core cannot sustain the radial pressure exerted by the surrounding ground: the core yields and, consequently, larger radial deformations $u$ develop ahead of the face, while both the radial and tangential stresses $\left(\sigma_{r r}, \sigma_{t t}\right)$ decrease (Fig. 11). This happens within the plastic zone, which extends, in this example, up to a distance of one-two radiuses ahead of the face (Fig. 9). As indicated by the peak in the tangential stress $\sigma_{t t}$ (at the boundary of the plastic zone at $r=a$ ), a stress 

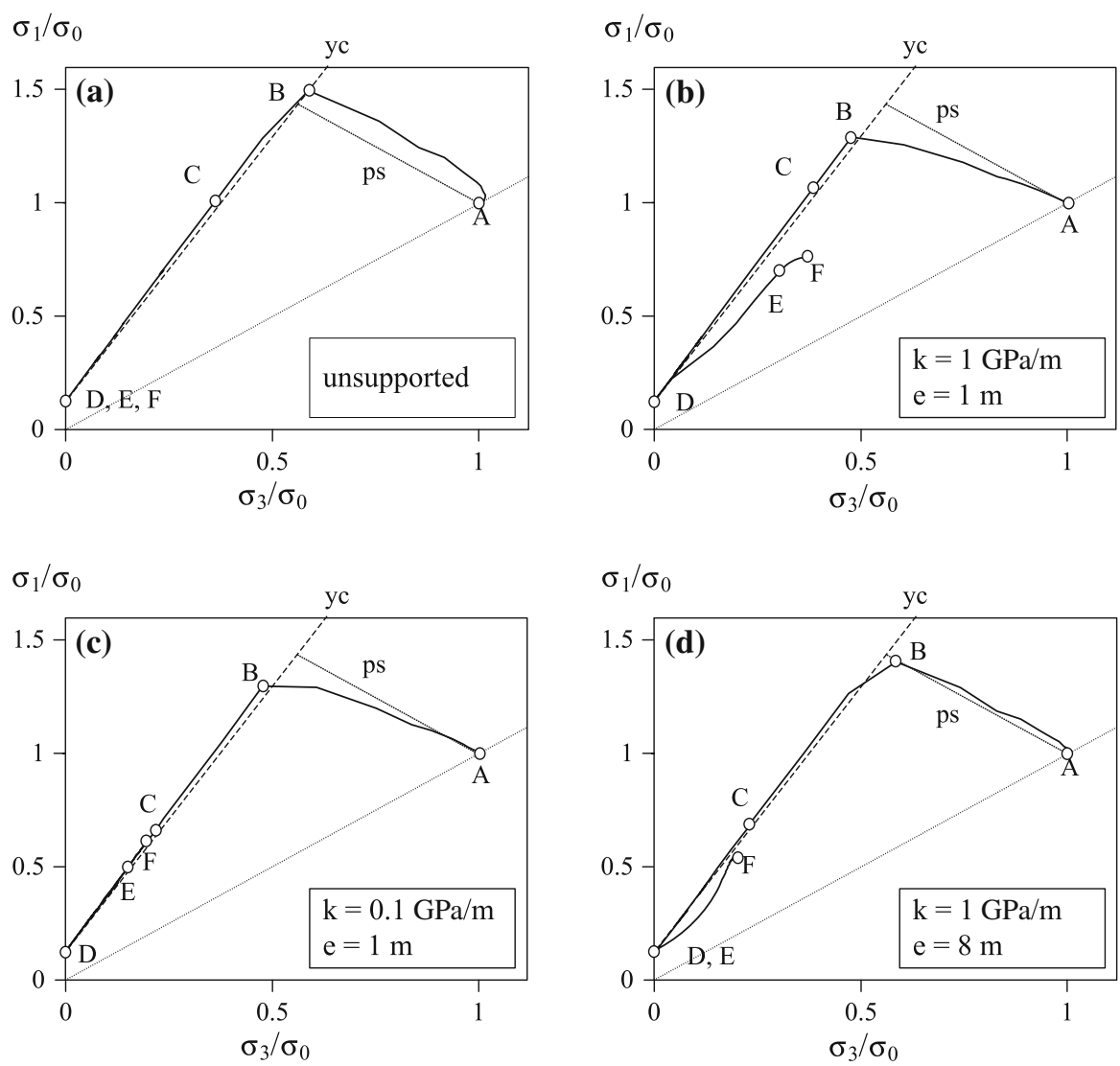

Fig. 10 Principal stress paths along the tunnel boundary (line $y c=$ yield condition, line $p s=$ elastic portion of the stress path under plane strain conditions, see Fig. 11 for the location of points $A$ to $F$ ). Note that the cases $\mathbf{b}$, $\mathbf{c}$, and $\mathbf{d}$ correspond to the points $A_{5}, A_{4}$, and $A_{3}$ of Fig. $6 \mathrm{~b}$, respectively

concentration occurs in the elastic region ahead of the plastic zone. Although this peak is slightly more pronounced if the tunnel is unsupported (Fig. 9a), Fig. 9 shows that the stress field ahead of the face is largely independent of the support characteristics.

At the face, the radial stress becomes equal to zero, while both the tangential and axial stresses $\left(\sigma_{t t}, \sigma_{y y}\right)$ become-in accordance with the assumed yield conditionequal to the uniaxial compressive strength $f_{\mathrm{c}}$. The continuation of excavation does not alter the stresses at the wall $(r=a)$ of an unsupported tunnel (Fig. 9a). In a supported tunnel, however, the radial stress at the tunnel wall remains equal to zero over the unsupported span $0<y<e$, but, afterwards, increases due to the installation of the lining, as the latter offers a resistance to the deformations of the ground caused by the subsequent excavation (Fig. 9b-d). The axial and tangential stress increase as well with the distance $y$ from the face, because the ground-on account of Coulomb's yield condition-is able to sustain more pressure in the tangential and axial directions due to radial confinement. In the case of a stiff lining 
(a)

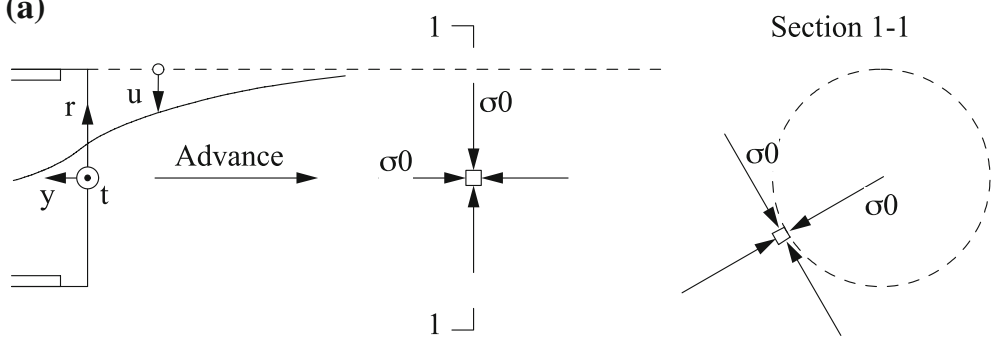

(b) 17
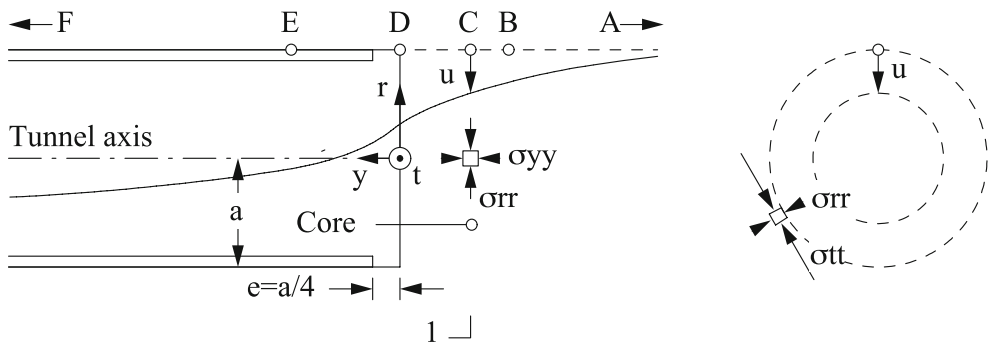

Fig. 11 a State prevailing in a cross section far ahead of the face. b Qualitative representation of the effect of the approaching excavation and location of the points $A$ to $F$ referred by Fig. 10

(Fig. 9b, d), the axial stress $\sigma_{y y}$ increases more rapidly than the tangential stress $\sigma_{t t}$ and becomes the highest principal stress. This is because a stiff lining facilitates arching in the longitudinal direction, particularly if installed close to the face (Fig. 9b). In the case of a soft lining (Fig. 9c), the ground at the excavation boundary also continues to yield after lining installation (both the axial and tangential stress increase with $\sigma_{r r}$, thus, fulfilling the yield condition of Coulomb).

Figure 10a shows the stress path in the principal stress space $\left(\sigma_{3}, \sigma_{1}\right)$ for an unsupported tunnel. The points $A$ to $F$ in the diagram refer to the location of the advancing face (see Fig. 11). The stress state reaches the yield condition at point $B$ ahead of the face, follows the yield condition down to point $D$ (which is located at the tunnel face), and remains constant afterwards. In the plastic zone developing around the opening (Fig. 9a), the deformations are partially irreversible and the stress field fulfils the yield condition.

In the presence of a stiff lining (Fig. 10b, d), the stress state reaches the yield condition slightly closer to the face, becomes bi-axial at the tunnel face (point $D$ ), and remains bi-axial over the unsupported span (stress state $D$ applies for $e<y<0$ ). With the development of radial pressure from the lining, however, the stress state again becomes elastic ("elastic re-compression," see Gärber 2003). The deformations within the so-called "past yield zone" (Fig. 9b, d) are partially irreversible, however, while the stress state is within the elastic domain (the ground in this region will have experienced yielding and irreversible deformations in the past). Figure 12 shows the results of a parametric study on the extent of the plastic 


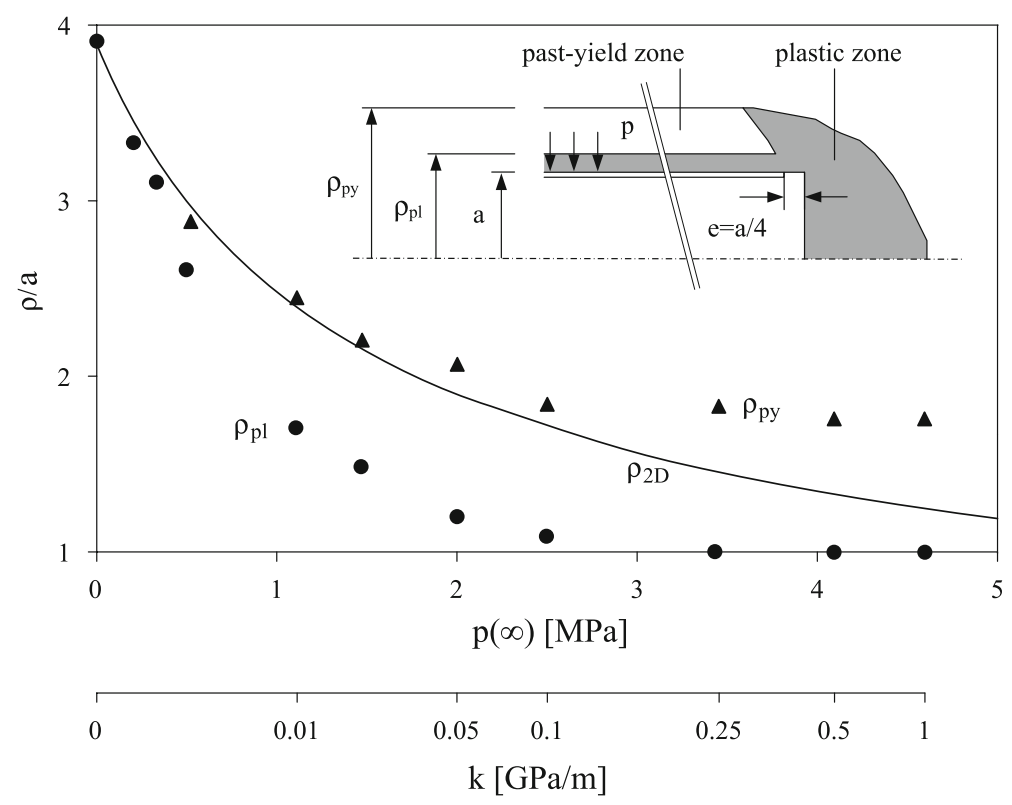

Fig. 12 Radius $\rho_{2 \mathrm{D}}$ of the plastic zone developing under plane strain conditions as a function of support pressure $p$ (solid curve), radius of the plastic zone $\left(\rho_{\mathrm{pl}}\right)$, and of the zone with past yielding $\left(\rho_{\mathrm{py}}\right)$ developing far behind the face under axisymmetric conditions for different values of the support stiffness $k$

zone. The marked points have been obtained by a series of axisymmetric calculations with different values of lining stiffness $k$ and show the radiuses $\rho_{\mathrm{pl}}$ and $\rho_{\text {py }}$ of the plastic zone and of the past yield zone, respectively, as well as the respective ground pressure $p(\infty)$ developing upon the lining far behind the face. Note that the plane strain analysis (solid curve $\rho_{2 \mathrm{D}}$ ) underestimates the extent of the region experiencing irreversible deformations in the case of stiff linings $\left(\rho_{2 \mathrm{D}}<\rho_{\text {py }}\right.$ at high $k$ values).

In the vicinity of the face, the longitudinal gradient of the radial displacement is large, because the core partially hinders the deformations (Fig. 13). Consequently,
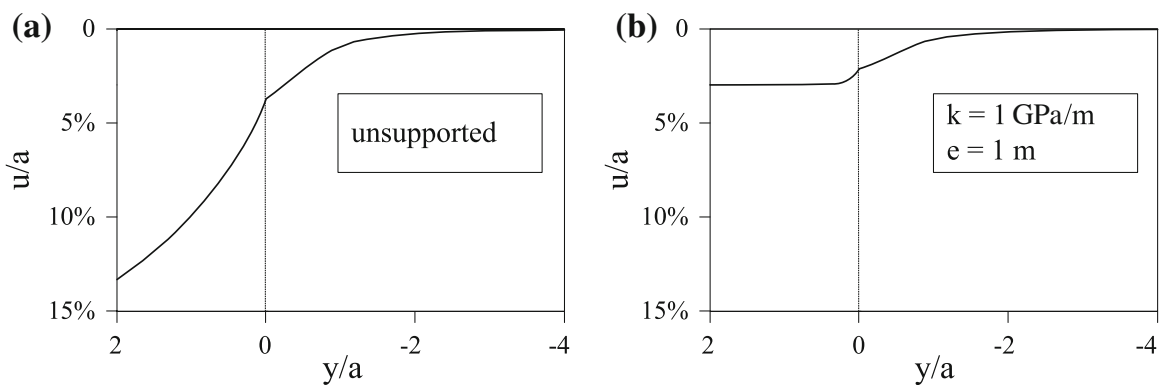

Fig. 13 Radial displacement $u / a$ along the tunnel boundary: a for an unsupported tunnel; $\mathbf{b}$ for a tunnel supported by a stiff lining installed close to the face (corresponds to point $A_{5}$ of Fig. 6b) 
(a)

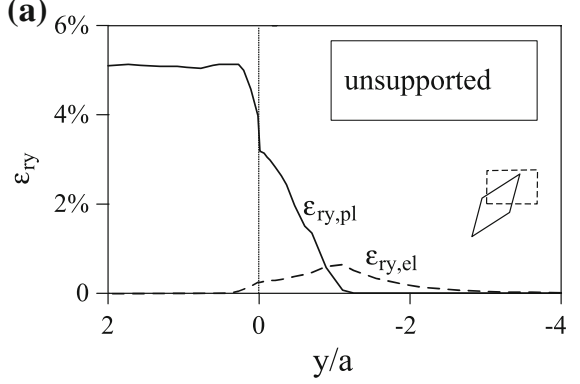

(b)

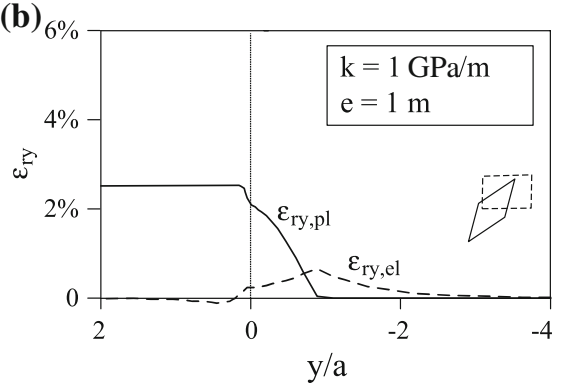

Fig. $14 \varepsilon_{\mathrm{ry}, \text { el }}, \varepsilon_{\mathrm{ry}}$, pl along the tunnel at $r / a=1.2$ : $\mathbf{a}$ for an unsupported tunnel; $\mathbf{b}$ for a tunnel supported by a stiff lining installed close to the face (corresponds to point $A_{5}$ of Fig. 6b)

the ground is subject to shearing and, thus, to a rotation of the principal stress axes in the $r-y$ plane. The rotation of the principal stress axes is temporary, as the shear stress $\sigma_{r y}$ disappears (the principal stresses are oriented in the radial, tangential, and axial directions) far ahead and far behind the face (Fig. 9). Note that the major part of the shear strain $\varepsilon_{r y}$ is irreversible (Fig. 14) and, consequently, the ground remains in an intensively sheared state (in the $r-y$ plane) far behind the face, although the shear stresses disappear (Fig. 9).

\subsection{Reasons for the Deviations in Ground Response}

The behavior of the axisymmetric model discussed in the last section has two particularly conspicuous features: (1) the development of irreversible shear strains in the $r-y$ plane associated with the rotation of the principal axes in the vicinity of the face; (2) the complete radial unloading of the excavation boundary over the unsupported span and an increase in radial stress following the installation of the lining.

In a plane strain analysis, it applies that: (1) the out-of-plane shear strains are, by definition, zero, while (2) the radial stress at the excavation boundary decreases monotonously from its initial value $\sigma_{0}$ to the support resistence $p(\infty)$. For these reasons, the features described above cannot be reproduced by a plane strain analysis and this might, therefore, explain the ground response deviations discussed in Sect. 3.

The results obtained for the case of an unsupported tunnel show, however, that point (1) cannot be responsible for the error of the plane strain model: the axisymmetric analysis leads, in spite of the large irreversible shear strains $\varepsilon_{r y}$ (Fig. 14a), to a final convergence, which is practically equal to the one obtained by the closed-form, plane strain solution (Fig. 6). Note also that, according to Figs. 6b and $7 \mathrm{~b}$, the distance of the ground response points $\left(A_{1}, 2,3, \ldots\right)$ from the plane strain ground response curve increases systematically with increasing lining stiffness, although the longitudinal convergence gradients and, consequently, the shear strains $\varepsilon_{r y}$ will decrease in the presence of a stiffer lining. Additional evidence of this is provided by axisymmetric analyses for the hypothetical case of a support that is installed immediately after excavation at the tunnel face and exerts right from the start a constant uniform pressure (i.e., $\sigma_{r r}=p(\infty)$ at $r=a$ for all $y>0$ ). The 
results for this case are given by the dashed curve plotted next to the plane strain solution (solid curve GRC) in Fig. 6b. The dashed curve practically coincides with the plane strain ground response curve, in spite of the plastic shear strains $\varepsilon_{r y}$ developing in the vicinity of the face. The stress path followed by the ground in this case is similar to the plane strain model in that the support does not allow for a complete radial de-stressing of the excavation boundary.

So, the deviation of the ground pressures developing upon a support must be due to the above-mentioned point (2), i.e., to the inability of any plane strain model to map the radial stress reversal that follows the installation of the lining. If this suggestion is true, then we would expect that the error introduced by the plane strain assumption will increase with the amount of radial stress reversal, i.e., with the length of the stress path portion $D F$ in Fig. 10 or, since stress state $D$ is biaxial, with the final pressure $p(\infty)$ and, thus, with the lining stiffness $k$ (the unsupported span $e$ being fixed).

Figure $6 \mathrm{~b}$ shows precisely this behavior. For example, the ground response point $A_{4}$ that results from the axisymmetric calculation for a soft support $(k=0.1 \mathrm{GPa} / \mathrm{m}$, installed at $e=1 \mathrm{~m})$ is closer to the plane strain ground response curve $(G R C)$ than the ground response point $A_{5}$ that applies to a stiff support $(k=1 \mathrm{GPa} / \mathrm{m}$, also installed at $e=1 \mathrm{~m}$ ). As can be seen from Fig. 10, the elastic re-compression that follows support installation is less pronounced in the case of a soft support (the path portion $D F$ is shorter in Fig. 10c than in Fig. 10b). In general, the stiffer the lining (the value of the unsupported span $e$ being fixed), the larger will be the deviation from the ground response curve.

Let us consider now the effect of an unsupported span $e$ for a fixed value of lining stiffness $k$. Cases b and d in Fig. 9 involve a stiff lining $(k=1 \mathrm{GPa} / \mathrm{m})$ installed at $e=1$ or $8 \mathrm{~m}$, respectively. The deviation from the ground response curve is larger in the case of the longer unsupported span (compare point $A_{3}$ with point $A_{5}$ in Fig. 6b). This is because the biaxial stress state (point $D$ in Fig. 10d), rather than the final stress state (point $F$ in Fig. 10d), governs the extent of the plastic zone (Fig. 9d) and the magnitude of deformation, since it prevails over the long unsupported portion of the tunnel. The deviation from the ground response curve, therefore, increases with the length $e$ of the unsupported span.

At the same time, however, the longer the unsupported span, the lower will be the final pressure $p(\infty)$, the smaller will be the difference between the final stress state and the temporary biaxial stress state, and the less pronounced will be the radial stress reversal. Consequently, the deviation from the ground response curve will also be smaller. The net effect of an unsupported span is, therefore, more complicated than that of lining stiffness. The error introduced by the plane strain assumption is small for linings installed close to the face, increases with the unsupported span $e$, but decreases again at very large values of $e$ (see, e.g., solid line for $k=1 \mathrm{GPa} / \mathrm{m}$ in Fig. 6b).

\section{Conclusions}

In the case of elasto-plastic material behavior, an axisymmetric model that takes into account the sequence of excavation and lining installation will always lead to ground response points above the plane strain ground response, i.e., the convergence 
corresponding to a certain ground pressure $p(\infty)$ will always be larger than the one obtained by a plane strain analysis. This is due to the inability of the plane strain model to map the radial stress reversal that follows the installation of the lining. In general, the stiffer the lining and the longer the unsupported span $e$, the larger will be the deviation from the ground response curve.

The convergence-confinement method, even in combination with advanced methods of pre-deformation estimation, underestimates the ground pressure and deformation, particularly for stiff linings, long unsupported spans, and heavily squeezing ground with highly non-linear material behavior. The inherent weakness of any plane strain analysis is that it cannot reproduce at one and the same time both the deformations and the pressures. This is relevant from the design standpoint, particularly for heavily squeezing conditions that require a yielding support in combination with an overexcavation: in this case, one needs reliable estimates of the deformations that must occur in order for the squeezing pressure to be reduced to a pre-defined, technically manageable level. In cases where the question of deformation is of secondary importance, however, a plane strain analysis in combination with an implicit method of pre-deformation estimation will suffice. For support completion close to the face, the differences in the results obtained by the different methods of analysis are not important from a practical point of view.

\section{Appendix: Consideration of Out-of-Plane Plastic Flow in the Ground Response Curve}

Radial and Tangential Stress Field

The radius $\rho$ of the plastic zone as well as the distribution of the radial and tangential stresses $\left(\sigma_{r r}, \sigma_{t t}\right)$ within the plastic zone $(a \leq r \leq \rho)$ can be determined without taking into account the deformations because the equilibrium equation:

$$
\frac{\mathrm{d} \sigma_{r r}}{\mathrm{~d} r}=\frac{\sigma_{t t}-\sigma_{r r}}{r}
$$

and the yield condition:

$$
\bar{\sigma}_{t t}=m \bar{\sigma}_{r r}
$$

where the overscore denotes the stress transformation:

$$
\bar{\sigma}=\sigma+\frac{f_{\mathrm{c}}}{m-1}
$$

form a system for the determination of the two stress components. Equation A2 presupposes that $\sigma_{r r}<\sigma_{y y} \leq \sigma_{t t}$. This condition is always satisfied (Reed 1988). Taking into account the condition:

$$
\left.\sigma_{r r}\right|_{r=a}=\sigma_{a}
$$

prevailing at the tunnel boundary as well as the requirement of stress continuity at the interface between the plastic and the elastic zone, i.e.: 


$$
\left.\bar{\sigma}_{r r}\right|_{r=\rho}=\frac{2 \bar{\sigma}_{0}}{m+1}
$$

the integration of Eqs. A1 and A2 leads to the well-known expressions:

$$
\bar{\sigma}_{a} \leq \bar{\sigma}_{r r}=\bar{\sigma}_{a}\left(\frac{r}{a}\right)^{m-1} \leq \frac{2 \bar{\sigma}_{0}}{m+1} \quad(\text { for } a \leq r \leq \rho)
$$

and:

$$
\frac{\rho}{a}=\left(\frac{2}{m+1} \frac{\bar{\sigma}_{0}}{\bar{\sigma}_{a}}\right)^{\frac{1}{m-1}} .
$$

Axial stress field

Assuming that plastic flow does not occur in the axial direction, i.e.:

$$
\varepsilon_{y y, p l}=0 \text {, }
$$

the out-of-plane elastic strain is also equal to zero:

$$
\varepsilon_{y y, e l}=\varepsilon_{y y}-\varepsilon_{y y, p l}=0,
$$

and on account of Hooke's law:

$$
\varepsilon_{y y, e l}=\frac{1}{E}\left(\left(\sigma_{y y}-\sigma_{0}\right)-v\left(\sigma_{r r}-\sigma_{0}\right)-v\left(\sigma_{t t}-\sigma_{0}\right)\right),
$$

the axial stress $\sigma_{y y}$ reads as follows:

$$
\sigma_{y y}=v\left(\sigma_{r r}+\sigma_{t t}\right)+(1-2 v) \sigma_{0},
$$

The assumption made (Eq. A8) presupposes that the axial stress is the strict intermediate stress, i.e.:

$$
\sigma_{r r}<\sigma_{y y}<\sigma_{t t}
$$

or, on account of Eqs. A2 and A11:

$$
(1-v(1+m)) \bar{\sigma}_{r r}<(1-2 v) \bar{\sigma}_{0}<(m(1-v)-v) \bar{\sigma}_{r r}
$$

One can readily verify that the first inequality is always satisfied: in a trivial manner if $v>(1-\sin \phi) / 2$ and due to Eq. A5 if $v<(1-\sin \phi) / 2$. The second inequality will be satisfied if:

$$
\bar{\sigma}_{r r}>\eta_{4} \bar{\sigma}_{0}, \text { where } \eta_{4}=\frac{1-2 v}{m(1-v)-v},
$$

i.e., if the radial stress is higher than a critical value. Taking into account that the lowest radial stress to be considered in the determination of the ground response curve is equal to zero:

$$
\bar{\sigma}_{r r} \geq \bar{\sigma}_{r r}(a)=\bar{\sigma}_{a} \geq \frac{f_{\mathrm{c}}}{m-1}
$$


the inequality A14 will be satisfied for the entire ground response curve if:

$$
f_{\mathrm{c}}>\sigma_{0} \frac{1-2 v}{1-v} .
$$

Incompressible materials $(v=0.5)$ fulfill this condition always. For $v<0.5$ and uniaxial compressive strength $f_{\mathrm{c}}$ lower than the value indicated by Eq. A16, however, the out-of-plane stress (Eq. A11) obtained under the assumption of no plastic flow in the axial direction (Eq. A8) will be higher than the tangential stress, thereby, violating the yield criterion (Fig. 15). In order to satisfy the latter, i.e.:

$$
\bar{\sigma}_{y y}=m \bar{\sigma}_{r r}
$$

plastic flow in the axial direction has to occur in the inner part of the plastic zone. The plastic flow does not influence the extent of the plastic zone $\rho$ or the radial and tangential stress field, because these are determined by the equilibrium and the yield conditions. Therefore, the radius $\rho^{\prime}$ of the inner part of the plastic zone can be calculated from Eqs. A6 and A14, while the radial stress at $r=\rho^{\prime}$ is given by the right hand side of inequality A14:

$$
\frac{\rho^{\prime}}{a}=\left(\eta_{4} \frac{\bar{\sigma}_{0}}{\bar{\sigma}_{a}}\right)^{\frac{1}{m-1}}, \quad \bar{\sigma}_{\rho^{\prime}}=\eta_{4} \bar{\sigma}_{0} .
$$

One can readily verify that $\rho^{\prime}<\rho$, i.e., the plastic zone consists of an outer ring with $\sigma_{r r}<\sigma_{y y}<\sigma_{t t}$ and an inner ring with $\sigma_{r r}<\sigma_{y y}=\sigma_{t t}$ (Fig. 15).

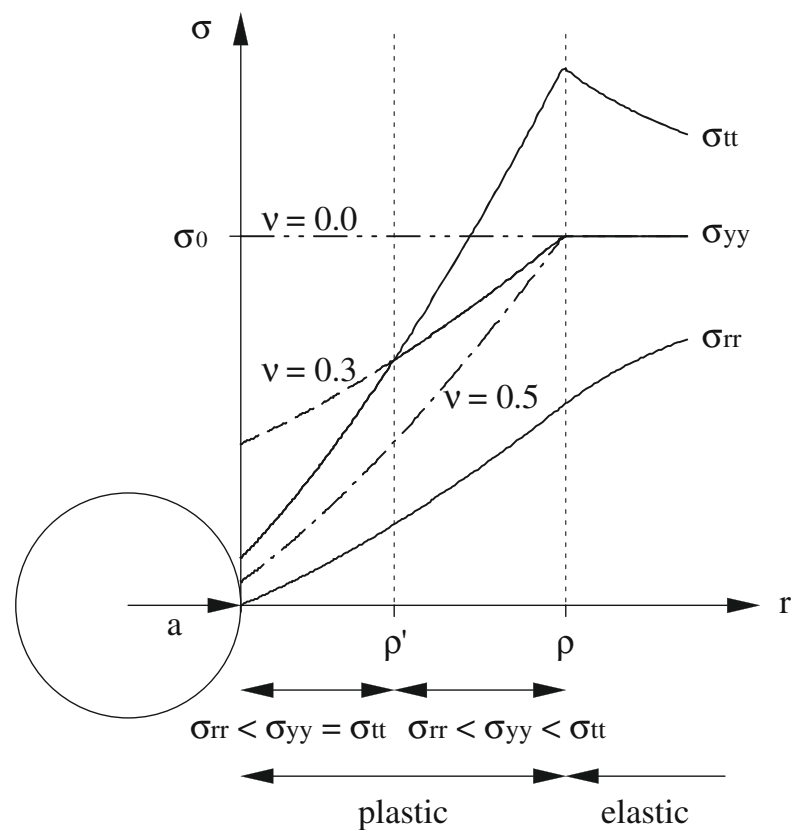

Fig. 15 Distribution of the radial stress $\sigma_{r r}$, of the tangential stress $\sigma_{t t}$, and of the axial stress $\sigma_{y y}$ for an unsupported tunnel ( $c=500 \mathrm{kPa}$; other parameters, see Table 1) 


\section{Deformation Field}

The stress states within the inner ring satisfy both Eq. A2 and A17. The corresponding plastic potential functions are:

$$
\begin{aligned}
& g_{1}\left(\sigma_{r r}, \sigma_{t t}, \sigma_{y y}\right)=\sigma_{t t}-\kappa \sigma_{r r}, \\
& g_{2}\left(\sigma_{r r}, \sigma_{t t}, \sigma_{y y}\right)=\sigma_{y y}-\kappa \sigma_{r r},
\end{aligned}
$$

where $\kappa$ depends on the dilatancy angle $\psi$ (Eq. 4). As the stress states are located on the edges of the Coulomb plastic potential surface (which has a pyramidoidal form in the principal stress space) and the latter is not continuously differentiable at the edges, the determination of the plastic strain increments proceeds according to Koiter (1953):

$$
\begin{gathered}
\mathrm{d} \varepsilon_{t t, p l}=\mathrm{d} \lambda_{1} \frac{\partial g_{1}}{\partial \sigma_{t t}}+\mathrm{d} \lambda_{2} \frac{\partial g_{2}}{\partial \sigma_{t t}}=\mathrm{d} \lambda_{1}, \\
\mathrm{~d} \varepsilon_{y y, p l}=\mathrm{d} \lambda_{1} \frac{\partial g_{1}}{\partial \sigma_{y y}}+\mathrm{d} \lambda_{2} \frac{\partial g_{2}}{\partial \sigma_{y y}}=\mathrm{d} \lambda_{2}, \\
\mathrm{~d} \varepsilon_{r r, p l}=\mathrm{d} \lambda_{1} \frac{\partial g_{1}}{\partial \sigma_{r r}}+\mathrm{d} \lambda_{2} \frac{\partial g_{2}}{\partial \sigma_{r r}}=-\kappa\left(\mathrm{d} \lambda_{1}+\mathrm{d} \lambda_{2}\right),
\end{gathered}
$$

where $\mathrm{d} \lambda_{1}$ and $\mathrm{d} \lambda_{2}$ denote the plastic multipliers. From these equations, we obtain:

$$
\varepsilon_{r r, p l}+\kappa\left(\varepsilon_{t t, p l}+\varepsilon_{y y, p l}\right)=0 .
$$

By taking into account the kinematical relations:

$$
\varepsilon_{r r}=\frac{\mathrm{d} u}{\mathrm{~d} r} \quad \text { and } \quad \varepsilon_{t t}=\frac{u}{r}
$$

as well as the strain decomposition:

$$
\varepsilon_{r r}=\varepsilon_{r r, e l}+\varepsilon_{r r, p l}, \quad \varepsilon_{t t}=\varepsilon_{t t, e l}+\varepsilon_{t t, p l}, \text { and } \quad \varepsilon_{y y}=\varepsilon_{y y, e l}+\varepsilon_{y y, p l}=0
$$

the relationship between the plastic strains (Eq. A24) leads to:

$$
\frac{\mathrm{d} u}{\mathrm{~d} r}+\kappa \frac{u}{r}=\varepsilon_{r r, e l}+\kappa\left(\varepsilon_{t t, e l}+\varepsilon_{y y, e l}\right) .
$$

This is a differential equation for the radial displacement $u$ because the right hand side is a known function of radius $r$ (the elastic strains are interconnected with the stresses via Hooke's law and the stresses are given by Eqs. A2, A6, and A17). The solution reads as follows:

$$
\begin{aligned}
u(r)= & u\left(\rho^{\prime}\right)\left(\frac{\rho^{\prime}}{r}\right)^{\kappa} \\
& +\frac{a}{E}\left(-\eta_{5} \bar{\sigma}_{a}\left(\frac{r}{a}\right)^{m}\left(\left(\frac{\rho^{\prime}}{r}\right)^{m+\kappa}-1\right)+\eta_{6} \bar{\sigma}_{0} \frac{r}{a}\left(\left(\frac{\rho^{\prime}}{r}\right)^{\kappa+1}-1\right)\right),
\end{aligned}
$$


where

$$
\eta_{5}=\frac{2 \kappa(m(1-v)-v)+1-2 m v}{m+\kappa}, \quad \eta_{6}=\frac{(1+2 \kappa)(1-2 v)}{\kappa+1},
$$

while the displacement $u\left(\rho^{\prime}\right)$ of the interface of the two plastic regions is obtained by applying Eq. 3 to the outer plastic ring:

$$
u\left(\rho^{\prime}\right)=\frac{\rho^{\prime} \bar{\sigma}_{0}}{E}\left(\delta_{1}+\delta_{2} \frac{\bar{\sigma}_{\rho^{\prime}}}{\bar{\sigma}_{0}}+\delta_{3}\left(\frac{\bar{\sigma}_{\rho^{\prime}}}{\bar{\sigma}_{0}}\right)^{-\delta_{4}}\right),
$$

where the radius $\rho^{\prime}$ and the contact pressure $\sigma_{\rho^{\prime}}$ are given by Eq. A18. The ground response curve is obtained from Eq. A28 for $r=a$ and can be written in the following form:

$$
u(a)=\frac{a \bar{\sigma}_{0}}{E}\left(\left(\delta_{1}+\eta_{1}\right)+\left(\delta_{2}+\eta_{2}\right) \frac{\bar{\sigma}_{a}}{\bar{\sigma}_{0}}+\left(\delta_{3}+\eta_{3}\right)\left(\frac{\bar{\sigma}_{a}}{\bar{\sigma}_{0}}\right)^{-\delta_{4}}\right)
$$

where

$$
\begin{aligned}
& \eta_{1}=-(\kappa(1-v)-v) \frac{(1-2 v)}{\kappa+1}, \quad \eta_{2}=(\kappa(1-v)-v) \frac{(m(1-v)-v)}{m+\kappa}, \\
& \eta_{3}=(\kappa(1-v)-v) \frac{(1-2 v)(m-1)}{(m+\kappa)(\kappa+1)} \eta_{4}^{\delta_{4}} .
\end{aligned}
$$

The coefficients $\eta_{1}, \eta_{2}$, and $\eta_{3}$ in Eq. A31 are the contributions of the out-of-plane plastic flow. These terms shall be considered in the determination of the following portion of the ground response curve:

$$
\bar{\sigma}_{a}<\eta_{4} \bar{\sigma}_{0} .
$$

The inequality (A33) has been obtained from Eq. A18 for $\rho^{\prime} / a>1$. One can readily verify by observing Eqs. 3 and A31 that the error of the simplified Eq. 3, defined as:

$$
\text { error }=\frac{\left.u(a)\right|_{\mathrm{Eq.} \mathrm{3}}-\left.u(a)\right|_{\mathrm{Eq.} \mathrm{A} 31}}{\left.u(a)\right|_{\mathrm{Eq} . \mathrm{A} 31}},
$$

depends on the normalized support pressure $\bar{\sigma}_{a} / \bar{\sigma}_{0}$, on the Poisson's ratio $v$, on the friction angle $\phi$, and on the plastic dilatancy angle $\psi$ (or, equivalently, on the material constants $m$ and $\kappa$ ).

\section{References}

AFTES (2002) Recommandations relatives à la methode convergence-confinement. Association Française des Travaux en Souterrain, Groupe de travail $\mathrm{n}^{\circ} 7$ (animé par M. Panet avec la collaboration de A. Bouvard, Dardard B, Dubois P, Givet O, Guilloux A, Launay J, Nguyen Minh Duc, Piraud J, Tournery H, Wong H). Tunnels et Ouvrages Souterrains, vol 170, pp 79-89

Amberg W (1999) Konzepte der Ausbruchsicherung für tiefliegende Tunnels. Bauingenieur 74(6):278283 
Anagnostou G (1992) Untersuchungen zur Statik des Tunnelbaus in quellfähigem Gebirge. Mitteilung des Institutes für Geotechnik der ETH Zürich, vol 201

Anagnostou G (2007a) The one-step solution of the advancing tunnel heading problem. In: Eberhardsteiner $\mathrm{J}$ et al (eds) ECCOMAS Thematic conference on computational methods in tunnelling

Anagnostou G (2007b) Continuous tunnel excavation in a poro-elastoplastic medium. In: Proceedings of the 10th International Symposium on Numerical Models in Geomechanics, NUMOG X, Rhodes, Greece, April 2007, pp 183-188

Anagnostou G, Kovári K (1993) Significant parameters in elastoplastic analysis of underground openings. ASCE J Geotech Eng 119(3):401-419

Barla M (2000) Stress paths around a circular tunnel. Rivista Italiana di Geotecnica 34(1):53-58

Barla G (2001) Tunneling under squeezing rock conditions. Eurosummer-School in Tunnel Mechanics, Innsbruck

Bernaud D (1991) Tunnels profonds dans les milieux viscoplastiques: approches expérimentale et numérique. $\mathrm{PhD}$ thesis, Ecole Nationale des Ponts et Chaussées

Bernaud D, Rousset G (1996) The new implicit method for tunnel analysis. Int J Numer Anal Meth Geomech 20:673-690

Bliem CH (2001) 3D finite element calculations in tunneling. Advances in geotechnical engineering and tunneling, vol 4. Logos Verlag, Berlin

Bonnier PG, Möller SC, Vermeer PA (2002) Bending moments and normal forces in tunnel linings. Paper presented at the 5th European Conference of Numerical Methods in Geotechnical Engineering, Paris, France, September 2002

Brinkgreve RBJ (2002) PLAXIS 2D, version 8. A.A. Balkema Publishers, Lisse, The Netherlands

Cai M, Kaiser PK, Uno H, Taska Y (2002) Influence of stress-path on the stress-strain relations of jointed rocks. In: Proceedings of the 2nd International Conference on New Development in Rock Mechanics and Rock Engineering, Shenyang, China,October 2002. Rinton Press, Princeton, USA, pp 60-65

Carranza-Torres C, Fairhurst C (2000) Application of the convergence-confinement method of tunnel design to rock masses that satisfy the Hoek-Brown failure criterion. Tunn Undergr Space Technol 15(2):187-213

Corbetta F (1990) Nouvelles méthodes d' étude des tunnels profonds-calculs analytiques et numériques. $\mathrm{PhD}$ thesis, Ecole des Mines de Paris

Corbetta F, Nguyen-Minh D (1992) Steady state method for analysis of advancing tunnels in elastoplastic and viscoplastic media. In: Pande GN, Pietruszczak S (eds) Numerical methods in geomechanics, pp $747-757$

Diederichs MS, Villeneuve M, Kaiser PK (2004a) Stress rotation and tunnel performance in brittle rock. Tunnelling Association of Canada Symposium, Edmonton, $8 \mathrm{p}$

Diederichs MS, Kaiser PK, Eberhardt E (2004b) Damage initiation and propagation in hard rock during tunnelling and the influence of near-face stress rotation. Int J Rock Mech Min Sci 41:785-812

Eberhardt E (2001) Numerical modelling of three-dimension stress rotation ahead of an advancing tunnel face. Int J Rock Mech Min Sci 38:499-518

Franzius JN, Potts DM (2005) Influence of mesh geometry on three-dimensional finite-element analysis of tunnel excavation. Int J Geomech 5(3):256-266

Gärber R (2003) Design of deep galleries in low permeable saturated porous media. PhD thesis, EPFL Lausanne

González-Nicieza C, Álvarez-Vigil AE, Menéndez-Diaz A, González-Palacio C (2008) Influence of the depth and shape of a tunnel in the application of the convergence-confinement method. Tunn Undergr Space Technol 23:25-37

Graziani A, Boldini D, Ribacchi R (2005) Practical estimate of deformations and stress relief factors for deep tunnels supported by shotcrete. Rock Mech Rock Eng 38:345-372

Guo C (1995) Calcul des tunnels profonds soutenus-Méthode stationnaire et méthodes approchées. PhD thesis, Ecole Nationale des Ponts et Chaussées

Kaiser PK (1980) Effect of stress-history on the deformation behaviour of underground openings. In: Proceedings of the 13th Canadian Rock Mechanics Symposium, Toronto, Canada, pp 133-140

Koiter WT (1953) Stress-strain relations, uniqueness and variational theorems for elasto-plastic materials with a singular yield surface. Q Appl Math 11:350-354

Kumasaka H (2007) Numerical computation of support characteristic curves for use in tunnel support design and their application to the characteristic curve method. Int J JCRM 3(1):1-6 
Lombardi G (1971) Zur Bemessung der Tunnelauskleidung mit Berücksichtigung des Bauvorganges. Schweiz, Bauzeitung, vol 89, Heft Nr. 32

Lombardi G (1981) Tunnel construction at great rock deformations. In: Proceedings of the International Tunnelling Congress-Tunnel 81, Düsseldorf, Germany, June 1981, pp 353-384

Martin D, Kaiser PK, Tannant D (1999) Stress path and failure around mine openings. In: Proceedings of the 9th ISRM International Congress on Rock Mechanics, vol 1. Paris, France, August 1999. Balkema, pp 311-315

Nguyen-Minh D, Berest P (1979) Etude de la stabilité des cavités souterraines avec un modèle de comportement élastoplastique radoucissant. 4eme Cong de la Soc Int De Méc Des Roches, Montreux vol 1, pp 249-255

Nguyen-Minh D, Corbetta F (1992) New methods for rock-support analysis of tunnels in elastoplastic media. In: Kaiser PK, McCreath DR (eds) Rock support in mining and underground construction, pp 83-90

Nguyen-Minh D, Guo C (1993) Sur un principle d' interaction massif-soutenement des tunnels en avancement stationnaire. In: Ribeiro e Sousa L, Grossmann NF (eds) Eurock '93, pp 171-177

Nguyen-Minh D, Guo C (1996) Recent progress in convergence confinement method. In: Barla G (ed) Eurock '96, pp 855-860

Nguyen-Quoc S, Rahimian M (1981) Mouvement permanent d'une fissure en milieu élastoplastique. J Mécanique Appliquée 5(1):95-120

Panet M, Guellec P (1974) Contribution à l'étude du soutènemant derrière le front de taille. In: Proceedings of the 3rd Congress of the International Society for Rock Mechanics, vol 2, Part B, Denver, Colorado, September 1974

Panet M (1995) Le calcul des tunnels par la méthode convergence-confinement. Presses de l'Ecole Nationale des Ponts et Chaussées, Paris

Pelli F, Kaiser PK, Morgenstern NR (1995) Effects of rock mass anisotropy and non-linearity on the near face stresses in deep tunnels. Rock Mech Rock Eng 28:125-132

Reed MB (1988) The influence of out-of-plane stress on a plane strain problem in rock mechanics. Int J Numer Anal Meth Geomech 12:173-181

Vogelhuber M, Anagnostou G, Kovári K (2004) The influence of pore water pressure on the mechanical behavior of squeezing rock. In: Proceedings of the 3rd Asian Rock Mechanics Symposium, Kyoto, Japan, November 2004 